\title{
The Impact of Supply Chain Disruptions on Stock Market Returns during Covid-19
}

Hélène Flore Nguemgaing

West Virginia University, anaclaudia.santanna@mail.wvu.edu

Ana Claudia Sant'Anna

West Virginia University, hfn00001@mix.wvu.edu

Follow this and additional works at: https://researchrepository.wvu.edu/faculty_publications

Part of the Agricultural and Resource Economics Commons

\section{Digital Commons Citation}

Nguemgaing, Hélène Flore and Sant'Anna, Ana Claudia, "The Impact of Supply Chain Disruptions on Stock Market Returns during Covid-19" (2021). Faculty \& Staff Scholarship. 3040.

https://researchrepository.wvu.edu/faculty_publications/3040

This Article is brought to you for free and open access by The Research Repository @ WVU. It has been accepted for inclusion in Faculty \& Staff Scholarship by an authorized administrator of The Research Repository @ WVU. For more information, please contact ian.harmon@mail.wvu.edu. 


\section{Emerald $\begin{gathered}\text { Agricultural } \\ \text { Finance Review }\end{gathered}$}

\section{The Impact of Supply Chain Disruptions on Stock Market Returns during Covid-19}

\begin{tabular}{|r|l|}
\hline Journal: & Agricultural Finance Review \\
\hline Manuscript ID & AFR-06-2021-0083.R1 \\
\hline Manuscript Type: & Research Article \\
\hline Keywords: & Event Study, Meat processors, Abnormal returns \\
\hline \multicolumn{2}{l}{} \\
\end{tabular}

\section{SCHOLARONE ${ }^{m}$ \\ Manuscripts}




\title{
The Impact of Supply Chain Disruptions on Stock Market Returns during Covid-19
}

\begin{abstract}
:
Purpose:

How has Covid-19 impacted meat processors' stock returns? We evaluate the effects of supply chain disruptions (e.g., lockdowns and Covid-19 incidences among workers) on stock market prices of meat processors during the COVID-19 pandemic.

Design/methodology/approach

This study uses an event study approach to examine the disruptions from COVID-19 through events such as plant shutdowns, the pandemic announcement, lockdown dates, and the first case of Covid-19 outbreaks in meat processing plants. Our dataset includes S\&P 500, Google Trends, financial beta, and data collected for 14 U.S. Publicly traded meat processing companies.

Findings

Results show that nationwide events (e.g., announcement of the pandemic) had no statistically significant impact on average abnormal returns of meat processing companies. Individually, however, firms experienced negative abnormal returns. Covid-19 related events in individual meat processing companies had a temporary negative abnormal return in the days prior to the event.

Originality/value

This study has two main contributions. First, we estimate the effect of Covid-19 on the returns of meat processors. Second, we use Google Trends to estimate the expected stock markets returns of meat processing companies. This study provides insight to investors on the behavior of industry returns from events such as outbreaks that affect human health.
\end{abstract}

Keywords: Event study, meat processors, abnormal returns

JEL Codes: Q13, Q14 


\section{Introduction}

According to USDA ERS (2020), the meat and poultry industry alone constitutes $30 \%$ of the food and beverage processing employees, an estimate of about 500,000 workers. The COVID19 pandemic has affected the food processing industry, precisely the meat supply chain. Pandemic control restrictions in meat processing and commercial activities caused retail and food services shortages, leading to a spike in meat product prices (Nayga and Zilberman 2020). Due to lockdown mandates closing offices, restaurants, and schools, the meat sector witnessed a decline in demand for bulk products and a rise in the demand for smaller packaged products sold in grocery stores (Tonsor and Shultz 2020). Meat processing facilities, however, were allowed to continue operations during the lockdown period. On April 28, 2020, President Trump signed an executive order classifying meat and poultry processing firms as an essential infrastructure requesting that they ensure continuous production and supply to Americans during the pandemic (The White House, 2020). Nevertheless, meat processing plants faced challenges brought on by Covid-19. Due to the close contact nature of the tasks carried out by meat processing workers, firms such as Tyson Foods Inc, Kraft Heinz Company, Seaboard Corporation experienced COVID-19 outbreaks among workers in their respective plants (Behlen, 2020; Butz, 2020; Helfrich, 2020; KY3 News, 2020; Mickelson, 2020; Reuters, 2020; Small, 2020). Between April and May 2020, a report from the CDC, which covered 264 processing plants in 28 states, showed that 17,358 workers were diagnosed with COVID-19, and 91 deaths were recorded (Waltenburg, 2020). These disruptions in the meat supply chain resulted in an abundance of livestock for slaughter and shortages of meat for sale to consumers (Domonoske, 2020). A question that remains unanswered is how these events affected the stock market returns of meat processing companies? Do we see an abnormal return brought on by these events, or were investors able to foresee them?

This research aims to evaluate how events during the COVID-191 ${ }^{1}$ pandemic, related to disruptions in the meat supply chain, impacted processing companies' stock market returns. The disruptions examined are: 1) the announcement of COVID-19 as a pandemic; 2) the first case of an outbreak in a meat processing plant; 3) outbreaks among employees in individual firms, and; 4) the lockdowns in various states due to Covid-19. This research sheds light on the stock market returns of meat processing companies in reaction to supply chain disruptions linked to COVID19. We also contribute by using google trend data to estimate expected returns. We have not yet seen the use of this data in forecasting stock market returns for agribusiness companies. Findings 
provide significant insights to investors on how sensitive stock market returns are to outbreaks that affect human health.

This paper is organized as follows: In the following section, we discuss the impact of Covid-19 on meat processing companies. Section 3 and 4 present the data used in the study and the empirical framework, respectively. Then, in Section 5, we discuss the empirical results. And lastly, section 6 unveils our conclusions and limitations of the study.

\section{Impact of COVID-19 on meat processing industries}

In the past decades, studies have focused on food-borne diseases and their consequences on financial markets. For instance, Pendell and Cho (2013) studied the reaction of stock markets to the Korean foot and mouth disease outbreaks between 2000 and 2010. They found that stock market reactions to the event was gradual with the cumulative abnormal returns (CAR) being more statistically significant than one day abnormal returns (AR). Jin and Kim (2008) analyzed the effects of the Bovine Spongiform Encephalopathy (BSE) outbreak on the security values of agribusiness and processing firms in the U.S. They find BSE had a negative impact on the beef industry and a negligible impact on companies that did not produce beef. Thompson et al. (2019) examined how the 2014-2015 highly pathogenic avian influenza (HPAI) affected agribusiness' stock markets. Results showed negative abnormal returns ranging from 2\% to 4\% for publicly traded meat processors' equities mainly after the event occurred. The impact was even higher (over $5 \%$ ) for firms specialized in poultry products.

Similarly, Moon and Tonsor (2020) investigated the effect of E. Coli recalls on prices of the U.S beef industry on 66 cases for over 14 years. Results show varying reactions to the change in the price of beef products to E. coli recalls across the different levels of vertical connection. Aggregated products being less affected by the recall event than disaggregated beef products. The current situation has reversed the side of the impact. Previously, the event focused on the final product due to issues related to animal health. In this study we focus on issues related to human health. Declared a pandemic on March 11, 2020, Covid-19 has impacted the agro-food supply chain logistics (Nayga and Zilberman, 2020).

Prior to COVID-19, meat processing industries had projected an increase in meat production in 2020 following the demand in the global market (Tonsor and Schulz, 2020). The 
beginning of the year 2020 saw an increase in meat production capacity. This created a level of assurance in the market about the availability of meat products throughout the year. However, with the onset of Covid-19, there was insufficient labour force to process all the livestock waiting to be slaughtered (some workers were laid-off, others voluntarily called off work to attend to family needs emerging from school and day-care closures). Equally, difficulties in maintaining social distancing inside the plants failed to contain outbreaks among employees, which lead to shutdowns and temporary closures (Kemp, 2020; KY3 News, 2020; Small, 2020; Telford \& Kindy, 2020).

The current COVID-19 global pandemic has imposed new challenges on meat processing plants. Among these challenges are: 1) The plant's design makes social distancing impossible amongst workers. The factories are structured so that workers carry out their tasks near each other. 2) The constant cold temperatures in the processing facilities allow for viruses to spread easily; 3 ) Due to the loud noise generated by the machinery, workers have to shout information over the noise to be heard, plus most workers do not wear face shields or face masks to shield themselves from saliva droplets. 4) Close contact between workers from on-site dormitories, production lines, and collective transportation makes the industry vulnerable to an outbreak. 5) Migrant workers with limited or no insurance benefits are more likely to conceal their infection to save jobs, increasing the risk of spreading the virus if infected (Reuben, 2020). The lack of effective preparedness for person-to-person transmission of the virus, absence of appropriate Personal Protective Equipment, and difficulties in implementing the guidelines to disinfect work areas also contributed to the rapid spread of the virus. Furthermore, the economic challenges faced by most workers at the time, coupled with the incentives offered by many meat processors, led many workers to still show up to work even if they had been in contact with someone who had tested positive for the virus (CDC, 2020).

In this study, we consider the period from January 2 to July 2, 2020. This timeframe includes the first reported incident of the virus in the Chinese Seafood wholesale market, the day U.S. COVID cases topped 2.7 million, U.S. states declaring stay-at-home order and, when U.S. death toll surpassed 128,000 casualties ( over 90 of deaths occurred in the meat and poultry processing facilities) (AS News, 2020; Waltenburg, 2020). These events on the developments of COVID-19 brought on reactions among investors.

A glance at the reaction of stock market returns during the study period is displayed in Figure 1. The effect from Covid-19 is visible: negative returns and higher volatility after the March 


\section{Data and Descriptive Statistics}

Meat processing firms were carefully selected from the 2019 top 100 meat and poultry processors (Gazdziak, 2020) and the USDA Meat, Poultry and Egg Product Inspection Directory 2020 (USDA, 2020), as well as related literature (Thompson et al., 2019). Specifically, we consider under meat processors companies those that are involved in one or more stages of meat processing (i.e. animal slaughtering, packaging and processing into products, such as sausage or lunch meat, delivers to retail stores (Encyclopedia of Food Microbiology, 2014)). The number of industries is limited to U.S. Headquartered and those that are publicly traded. Together the 14 firms account for more than $60 \%$ of the beef market, about $65 \%$ of the poultry market, and about $30 \%$ of the pork market in the U.S.(Csimarket, 2020). Daily adjusted closing stock prices for the firms and the S\&P 500 from January 2 to July 2, 2020, came from Yahoo Finance and Mergent Online. We estimated returns by subtracting the current adjusted closing price of the firm from the previous day's adjusted closing price over the previous day's adjusted closing price, then multiply by 100 . All returns are in percentages. Table 1(a) and 1(b) presents the summary statistics of the 14 firms' returns, the S\&P 500 Index returns, and the Google search of the word coronavirus and meat processor. Out of the fourteen firms, nine show negative mean returns. The S\&P 500 also has 
negative mean returns during the period analyzed. Chef's Warehouse Inc. has the lowest average return among all firms while MamaMancini’s Holdings, Inc. has the highest.

In addition to using the S\&P 500 to predict the meat processing companies' expected returns, we also use Google trends. The use of Google Trends in research is not new (Jun et al., 2017), yet, we believe to be the first to use it in the scope of agricultural finance. Researching 657 papers (Jun et al., 2017) have found that Google trends have been increasingly used as a forecasting tool over recent years. Similarly,(Bijl et al., 2016) find that there is "economical value" to use Google Trends when forecasting stock returns. Yoshinaga and Rocco (2020) find that increasing Google search volume has an inverse relationship with stock market returns, while Swamy and Dharani (2019) find a positive relationship. Salisu et al., (2021) argue that Google Trends shape investor sentiments and can be used to measure how an investor may predict the behavior of stock market returns. As such, we expect that variations in Google searches reflect investors' trying to gain knowledge on the pandemic and forecast its impacts on the stock market (Brodeur et al., 2021). In trying to anticipate market reactions in the U.S. due to events occurring in China, investors would use the world wide web to search for terms related to the disease (e.g. coronavirus) and/or to the industry (e.g. meat processors).

Google search data was obtained from Google Trends made available by Google Analytics. Search from Google Trends reports an index the daily and weekly volumes of search organized by geographical location and by category made from the Google search engine (Choi and Varian, 2012). The results are by topic and provide the query index data of the word that is searched on Google. In this study, we narrowed our search to the words "coronavirus" and "meat processors". We use the term "meat processor" to check how robust our results are to the changes in the search word. The term "coronavirus" presented more significant variation and early on search peaks than the other terms (e.g. coronavirus case, lockdown, meatpacking plant, meat shortage, and COVID19). In fact, the word "coronavirus" was at the top of all words search on Google Trends for three consecutive months in the U.S. (February 17- May 7, 2020), seconded by weather. The day after the pandemic was announced, on March 12, Google Trends data shows that the word hit the highest index level, 100. We believe that investors needed to understand what coronavirus is to speculate the impact on the meat industry.

\subsection{Events and data}


In this study, we analyzed four events and their impact on the stock market returns of meat processing industries:

Event 1: March 11, the WHO declares COVID-19 a pandemic (firms face same event date) Event 2: March 23, the first case of COVID-19 in a meat processing plant (firms face same event date)

Event 3: First cases of COVID-19 in each of our selected firms (event dates differ in each firm) Event 4: Lockdown dates at each plant for each of our firms (event dates according to firm location)

Dates for events 3 and 4 were collected from news articles and publications (Behlen, 2020; Butz, 2020; Kocher, 2020; KY3 News, 2020; Mickelson, 2020; Small, 2020). These dates relate to firms' shutdown announcements and halt in production due to workers testing positive for COVID-19 (Table 2). Cases of employees getting sick were reported all over the country between March and May. For instance, Tyson and Kraft Heinz Company, Seaboard Corporation all reported cases of COVID-19, which led to the shutdown of their meat processing plants. When a selected meat industry did have an event date, we used the dates of a firm that experienced outbreaks in the same geographic area or when the first confirmed outbreak case was reported.

\section{Empirical framework}

The event study approach estimates the impact of a specific event on the value of firms (MacKinlay, 1997) by using financial market data to assess the effect of an economic event. It assumes that informal or formal information can cause an immediate reaction on the financial market on the event day and thereafter. Therefore, event windows are evaluated around the event dates instead of on the specific event date (Thompson et al., 2019). The event window is used to control for the possibility that the investors might have acquired unofficial information well in advance of the official information being released, causing them to make decisions about stock prices. The event windows are counted in terms of days and can go from $(-10+10),(-5$ to +0$),(-$ $5 ;+5),(0 ;+5),(0 ;+10)$ days. 
Several steps were conducted to perform an event study analysis. First, we defined the event of interest. Then, using the data afore described, we estimate the expected returns. The expected returns represent returns that would have been realized if the COVID-19 outbreaks had not occurred. The difference between actual returns and expected returns over the event window is the abnormal returns. Finally, we investigated whether abnormal returns were observed due to the four events aforementioned.

We predict expected returns by regressing stock returns on the returns from a stock index (e.g. S\&P 500) in the period (i.e. window) before the event. The market index picks up the market fluctuations, which is different from the firm-specific factors. To further reduce our $\operatorname{Var}(e)$, we proceed by adding one more explanatory variable, the Google Trends, and using the augmented market $\operatorname{model}^{1}$ :

Stock return $_{i t}=a_{i}+\beta_{i}$ Returns Market Index return $_{i t}+\delta_{i}$ GoogleTrends $_{i t}+\varepsilon_{i t}$

where Stock return $i t$ is the stock market return for firm $i$ on date $t$ during 120 days trading days estimation period. $a, \beta$, and $\delta$ are the intercept and coefficients of market index returns and Google Trends, respectively. $\varepsilon_{i t}$ is an error term with an expected value of zero and a constant variance. We used the predicted returns $\left(\right.$ StockReturn $_{i t}$ ) as an estimate for the expected returns. We obtained the abnormal returns by subtracting expected returns from the actual returns (proxied by the market index returns). So, for every firm $i$, and at specific date $t$ we had (Thompson et al., 2019):

$$
\text { Abnormal Return }_{i t}=\text { Actual Returns }_{i t}-\text { Stock Return }_{i t}
$$

where the Actual Returns are the stock market returns observed during the event window and the expected returns are those predicted by equation (1) (i.e. Stockretur $n_{i t}$ ). Next, we estimate the Average Abnormal Return (Avg. Abnormal Ret.) on date $t$ which is the sample mean (Thompson et al., 2019):

\footnotetext{
${ }^{1}$ We also predicted the expected returns using only the stock market index (i.e. market model): Stock return $n_{i t}=a_{i}$ $+\beta_{i}$ Returns Market Index return $_{i t}+\varepsilon_{i t}$
} 
Where Avg. Abnormal Ret.t represents the average absolute return at date t. After obtaining the abnormal return, it is important to determine if it is significantly different from zero. We used a $95 \%$ confidence interval to assess whether the average abnormal rate of return was statistically significant.

Additionally, we used the K.P. test introduced by Kolari and Pynnonen (2010) and the Generalized Rank Test (GRANK), proposed by Kolari and Pynnonen (2011), to test for abnormal returns for each company with different window specifications. These tests were also used to test whether Cumulative Abnormal Returns (CARs) were statistically significant (Pacicco et al., 2017):

Cumulative Abnormal Return $n_{i}\left(t_{1}, t_{2}\right)=\sum_{t=t_{1}}^{t_{2}}$ Abnormal Return $_{i t}$ Where $t_{1}<t_{2}$ with $t_{1}, t_{2} \in$ (event window). The K.P. test corrects for the cross-sectional correlation of the abnormal returns present in the BMP test introduced by Boehmer et al., (1991). Although the Kolari and Pynnonen (2010) (K.P.) test statistic is also known to deliver a robust parametric test, it has the disadvantage that it relies on the assumption that returns are normally distributed. Thus, it may underperform in the event where returns are not normally distributed (Pacicco et al., 2017). Hence, we use the Kolari and Pynnonen (2011) Generalized Rank Test (GRANK), which does not depend on any normal distribution. Like all nonparametric statistics, it does not require assumptions on the distributions of returns. The Kolari and Pynnonen (2011) Generalized Rank Test (GRANK) has the advantage that it outperforms the previous test in that it accounts for both the event-induced volatility and the serial correlation of abnormal returns within the event windows for each of the firms (Pacicco et al., 2017).

We further checked for robustness using a Google search term more specific to the industry ("meat processor") and included a more traditional financial concept (the financial beta). Results are presented for these estimations. Beta measures the volatility of a stock against the market at large and is typically determined by a reference market index. To calculate beta, we divide the covariance between the stock return and the market return by the variance of the market return. The greater the beta of a stock, the more risky the stock (Infront Analytics, 2021). The use of beta 
to forecast stock market returns is controversial in the literature. While older studies have shown that there are no empirical relation between betas and returns more recent studies have provided evidence that there is (see (Isakov, 1999) and (Elsas et al., 2003)).

\section{Results and Discussion}

Our results are delivered for each of the four events of interest. Figures 2 to 5 show the cumulative change in response series in percentages (i.e the cumulative abnormal returns) for the respective event for ten trading days before and after the event day(t=0). Figures 2 to 5 allow for the comparison of the statistical significance of the abnormal returns estimated with each model (market model, augmented market model with Google Trends ("coronavirus") and the augmented market model with Google Trends ("meat processor") and the financial beta. In each figure, the 95\% confidence interval is represented by the dotted lines. Results on the K.P. and GRANK tests performed on returns for each company are displayed in Tables 3 to 6 . These allow for comparison between the three models.

\subsection{The event on March 11, the pandemic announcement}

Figures 2(a) to 2(c) show the impact of the pandemic announcement on abnormal market returns. The average abnormal returns are small in the days before the event, becoming negative a couple of days after the event and becoming positive just before the tenth day after the event. This movement follows that of our initial analysis of the raw data (Figure 1). However, the 95\% confidence interval indicates that the announcement by WHO of COVID-19 being a pandemic had no statistically significant effect on average abnormal returns for the meat processing firms. Therefore, on average, there was no impact beyond what would have been expected. Perhaps there were expectations from investors of the effects of COVID-19 on stock markets, hence the lack of statistically significant abnormal returns. Comparing Figures (2b) and (2c) we do not find that the use of a different search word affects our findings. Looking at the cumulative abnormal returns (CAR) in Table 3(e) \& (f), we notice that in both K.P. and GRANK test results, the windows (-5, $+5)$ are significant for most firms when observed individually

Similarly, when we include the Google Trends in Table 3(a) \& (b), for the window $(-5,5)$, we see that the number of firms' with returns that are significant at $1 \%$ increases and that the CARs are 


\subsection{The first case of Covid-19 in a meat processor: March 23}

Figures 3(a) to 3(c) show the cumulative abnormal returns without and with Google Trends and financial beta when the first firm's case of the outbreak occurred. Looking at the results, we can see transitory negative abnormal returns few days before the event day and positive abnormal returns after the event. The inclusion of Google Trends shifts the trading day when the abnormal returns switch from negative to positive. Results from the KP and GRANK tests (Tables 4(a) to 4(f)) show how the event impacted the cumulative abnormal returns for each company differently. This may be explained by the fact that the event occurred only in one firm at a specific location. Although the news reported an outbreak in the meat industry, it had little impact on the cumulative abnormal returns of some other meat processors, possibly because they could carry on with production as usual. In fact, Lusk et al. (2020) find that although there were outbreaks in processing firms, leading to plant closure of meatpacking plants, it did not obstruct others from producing meat products. The use of Google Trends increases the number of companies with a statistically significant cumulative abnormal return. We also find a similar result when we estimate with the term meat processor and financial beta. Looking at the CAR results with Kolari and Pynnonen (2010) K.P. test (Table 4a) with Google Trends for the event windows $(-5,+5)$, by examining the firms individually, nine out of fourteen firms report some level of significant abnormal returns with only one negative significant return (CHEF, -60.7 percent). Without Google Trends (Table 4 e), only six firms are statistically significant, including one statistically significant negative return (CHEF, -59.8 percent). The event window $(0,5)$ shows more firms with negative returns (ten negative abnormal returns out of fourteen).

\subsection{The first case of Covid-19 in each individual firms}


Figure 4(b) shows the cumulative abnormal returns with Google Trends ("coronavirus") for the first case of the Covid-19 outbreak in each individual firm. Results show that firms had a temporary negative effect on the average abnormal returns days prior to the event. This effect quickly dissipates after the event date and becomes positive but not significant. Without Google Trends, the cumulative abnormal returns remain negative up to ten days after the event day (Figure 4a). Figures 4(a) to 4(c) show how the cumulative average abnormal returns of the meat processing industry have been impacted prior to the outbreak cases in the companies. The results reported in Table 5(a) to 5(f) showed the individual reactions of the cumulative abnormal returns for each of the firms when the first cases of the outbreak occurred. We notice that when we control for the inclusion of the term "Meat Processors" and the financial beta companies, in general, experience a positive and statistically significant cumulative abnormal return, individually, after the first outbreak in the companies. Although this result may seem counter-intuitive, Lusk et al. (2020) argue that stock market prices of meat processors (especially those with packing operations) did not experience large declines due to Covid-19 events. Also, companies may have focused their efforts on producing higher-value products to make up for their increased costs while halting the production of lower-value products.

\subsection{The lockdown for individual firms}

Figure 5 shows the cumulative average abnormal returns for the start date of the lockdown in each of the firms' states. Overall, we observe temporary negative abnormal returns prior to the event day for Figures 5(a) to 5(c) with positive or close to zero cumulative average abnormal returns after the event day. In terms of the cumulative average abnormal returns, we do not observe any to be statistically significant (Figure 5(a) to 5(c)). Tables 6(a) to 6(f) show that the lockdown had varying effects on the cumulative abnormal returns for each company. In general, companies experience negative cumulative abnormal returns prior to the lockdown and positive after. These results are possibly linked to the fact that meat processors were allowed to continue functioning during the lockdown. CHEF shows negative significant abnormal returns both with and without Google Trends on a range of -107.7 to +55.92 percent during the lockdown in its location (Table $6 \mathrm{a}$ and $6 \mathrm{c})$. PPC and BRID do not record any significant abnormal returns without Google Trends in Table 6c, whereas when included, the returns are significant on average in both Table 6a and 6b. Other firms like SEB, MMMB, CALM, MDLZ show, on average, no significant returns 
whether with or without Google Trends. These results also go to show that firms had different reactions during the lockdown period, and we can link that to the ability of the firms to adapt to the changes brought by the pandemic by taking into consideration the diversity in customer base and the flexibility in the supply chain (Hobbs, 2021).

\section{Conclusion}

This study examined the effects of events that disrupted supply chains on the stock market returns of meat processing companies during the pandemic. We apply the event study approach to investigate events such as the pandemic announcement, the first case of COVID-19 outbreak in meat processors, the first case of an outbreak in individual meat processors, and the first lockdown days. Results show that nationwide events had, on average, no statistically significant effect on the cumulative average abnormal returns of meat processing companies. Individually, however, some firms experienced negative cumulative abnormal returns. We also found that Covid-19 related events to individual companies had only a temporary negative effect on the meat processing returns and sometimes positive effects after the event. The findings of Moon and Tonsor (2020) on the impact of E. coli recalls on the U.S beef industry are in line with these results. They find a temporary negative effect on the U.S beef industry for about four days, followed by a quick recovery to expected returns. Similarly, the findings of our study are consistent with those of Thompson et al. (2019), that found heterogeneity in the reactions of investors based on the nature of the events and the timing of the event during the period of study. Furthermore, our results are supported by the findings of Jin \& Kim (2008) on the effects of the BSE outbreak on the security values. They also find that while the events negatively impacted some firms, other firms experienced stronger positive benefits.

The use of Google Trends allowed for a better representation of investor's perceptions and improved the estimation of expected returns. Like Brodeur et al. (2021) and Salisu et al.(2021), we argue that the variation in google searches reflects both the investors' knowledge and concern about the pandemic and its impact on the stock market. Thus, in general, investors were able to predict the behavior of the stock markets. The use of the term and of other traditional financial concepts can also help improve the prediction of expected returns. However, it is important to shed 
light on some limitations of our research. First, we only consider the U.S. publicly traded meat processing companies; as such, important privately owned meat processors were not considered (e.g. Smithfield). Secondly, meat processors in our study may produce and distribute other products that are not meat products. As such, companies with a greater diversity in products other than meat may have suffered a lesser or different impact from the events than those with a larger share of activities devoted to meat processing. We suggest that future studies focus on developing an event study methodology that can account for how diversified a company's product portfolio is. This study provides insight to investors on the behavior of industry returns from events such as outbreaks that can disrupt supply chains. We also provide insight into how the use of search trends can improve the estimation of expected stock market returns. 


\section{References}

AS News. (2020). Coronavirus USA: Live news summary for Thursday 2 July. AS.Com. available at : https://en.as.com/en/2020/07/02/latest_news/1593643054_879458.html (accessed 03 July 2020)

Bayly, L. (2020). Dow ends the day up 2,000 points as \$2T stimulus bill takes shape. NBC News. available at: https://www.nbcnews.com/business/markets/dow-soars-1-100-pointsopening-bell-hopes-economic-stimulus-n1167526 (accessed 24 March 2020)

Behlen, A. (2020). Flatonia Area Egg Facility Has Nine Employees Test Positive for Covid |The Fayette County Record. available at:

https://www.fayettecountyrecord.com/news/flatonia-area-egg-facility-has-nineemployees-test-positive-covid (accessed 15 April 2020)

Bijl, L., Kringhaug, G., Molnar, P., \& Sandvik, E. (2016). Google Searches and Stock Returns. International Review of Financial Analysis, 45, pp.150-156. https://ssrn.com/abstract $=2756370$

Boehmer, E., Masumeci, J., \& Poulsen, A. B. (1991). Event-study Methodology under conditions of event-induced variance. Journal of Financial Economics, 30(2), pp.253-272.

Brodeur, A., Clark, A. E., Fleche, S., \& Powdthavee, N. (2021). COVID-19, lockdowns and well-being: Evidence from Google Trends. Journal of Public Economics, 193. https://doi.org/10.1016/j.jpubeco.2020.104346

Butz, D. (2020). Seaboard Triumph Foods worker dies of COVID-19. Sioux City Journal. available at :https://siouxcityjournal.com/news/local/seaboard-triumph-foods-workerdies-of-covid-19/article_8146941e-1d1b-5586-9d91-d7b6a9b01f14.html (accessed 04 May 2020) 
CDC. (2020). Communities, Schools, Workplaces, \& Events. Centers for Disease Control and Prevention. available at: https://www.cdc.gov/coronavirus/2019ncov/community/organizations/meat-poultry-processing-workers-employers.html (accessed 30 April 2020)

Choi, H., \& Varian, H. (2012). Predicting the Present with Google Trends. Economic Record, 88(s1), 2-9. https://doi.org/10.1111/j.1475-4932.2012.00809.x

Csimarket. (2020). Tyson Foods Inc Competition Market share by Company's SegmentCSIMarket. available at: https://csimarket.com/stocks/competitionSEG2.php?code=TSN (accessed 12 August 2020)

Domonoske, C. (2020). Empty Grocery Shelves Are Alarming, But They're Not Permanent. NPR.Org. available at: https://www.npr.org/2020/03/18/817920400/empty-groceryshelves-are-alarming-but-theyre-not-permanent(accessed 18 March 2020)

Elsas, R., El-Shaer, M., \& Theissen, E. (2003). Beta and returns revisitedEvidence from the German stock market. International Finance Markets, Institutions and Money, 13, 1-18. Encyclopedia of Food Microbiology. (2014). Meat Processing-An overview | ScienceDirect Topics. In ScienceDirect.com (Second Edition). https://www.sciencedirect.com/topics/agricultural-and-biological-sciences/meatprocessing

Gazdziak, S. (2020, September 23). 2020 Top 100 Meat and Poultry Processors Report. The National Provisioner. https://www.provisioneronline.com/2020-top-100-meat-andpoultry-processors 
Helfrich, J. (2020). BREAKING NEWS: Rochelle Foods plant ordered to close due to COVID-19 outbreak. available at :https://www.newstrib.com/2020/04/17/breaking-news-rochellefoods-plant-ordered-to-close-due-to-covid-19-outbreak/aglaege/(accessed 17 April 2020)

Hobbs, J. E. (2021). The Covid-19 pandemic and meat supply chains. Meat Science. https://doi.org/10.1016/j.meatsci.2021.108459

Infront Analytics. (2021). International Agricultural Products: Levered/Unlevered Beta (IFAP | EGY $\mid$ Farming \& Fishing)—Infront Analytics. https://www.infrontanalytics.com/feEN/30755KE/International-Agricultural-Products/beta

Isakov, D. (1999). Is beta still alive? Conclusive evidence from the Swiss stock market. The European Journal of Finance, 5(3), 202-212. https://doi.org/10.1080/135184799337046

Jin, H. J., \& Kim, J.-C. (2008). The effects of the BSE outbreak on the security values of US agribusiness and food processing firms. Applied Economics, 40(3), pp.357-372. https://doi.org/10.1080/00036840500461824

Kemp, A. (2020). 116 COVID-19 infections found in pork processing plant in Guymon. Austin American-Statesman. available at: https://www.statesman.com/news/20200504/116covid-19-infections-found-in-pork-processing-plant-in-guymon (accessed 4 May 2020)

Kocher, S. (2020). Updated: Cold Spring Pilgrim's Pride facility has taken extensive safety measures, company says. St. Cloud Times. available at : https://www.sctimes.com/story/money/business/2020/04/23/concerns-rise-potentialcovid-19-exposure-pilgrims-pride-cold-spring-st-cloud-gnp/3011554001/(accessed 23 April 2020)

Kolari, J., \& Pynnonen, S. (2010). Event Study testing with cross-sectional correlation of abnormal returns. Review of Finance Studies, 23(11), pp.3996-4025. 
Kolari, J., \& Pynnonen, S. (2011). Nonparametric Rank Tests for Event Studies. Journal of Empirical Finance, 18, pp.953-971. https://doi.org/DOI: 10.2139/ssrn.1254022

KY3 News. (2020). Kraft Foods plant in Springfield closes for “deep cleaning” after two employees test positive for COVID-19. Https://Www.Ky3.Com. available at: https://www.ky3.com/content/news/Kraft-Foods-plant-in-Springfield-closes-for-deepcleaning-after-two-employees-test-positive-for-COVID-19-569204641.html(accessed 29 March 2020)

Lusk, J., Tonsor, G., \& Schulz, L. (2020). Beef and Pork Marketing Margins and Price Spreads during COVID-19. Applied Economics Perspectives And Policy, 43(1), pp.4-23. https://doi.org/10.1002/aepp.13101

MacKinlay, A. C. (1997). Event Studies in Economics and Finance. Journal of Economic Literature, 35(1), pp.13-39. JSTOR.

Mergent. (n.d.). Mergent Online. Retrieved August 14, 2020, from https://www.mergentonline.com/login.php

Mickelson, G. (2020). Tyson Foods CEO Provides Update on Efforts to Address COVID-19. available at:https://www.tysonfoods.com/news/news-releases/2020/4/tyson-foods-ceoprovides-update-efforts-address-covid-19 (accessed 6 April 2020)

Moon, D., \& Tonsor, G. (2020). How Do E. coli. Recalls Impact Cattle and Beef Prices? Journal Agriculture and Resource Economics, 45(1), 92-106.

Muccari, R., Chow, D., \& Murphy, J. (2020). Coronavirus timeline: Tracking the critical moments of COVID-19. NBC News. available at:https://www.nbcnews.com/health/health-news/coronavirus-timeline-tracking-criticalmoments-covid-19-n1154341 (accessed 10 March 2020) 
Nayga, R. M. J., \& Zilberman, D. (2020). Research Priorities to Fill Critical Knowledge Gaps Caused by the Coronavirus Pandemic. CAST Commentary QTA2020-3, pp.34-35.

Pacicco, F., Vena, L., \& Venegoni, A. (2017). Running event studies using Stata: The estudy command.p.14. http://dx.doi.org/10.2139/ssrn.3059521

Pendell, D. L., \& Cho, C. (2013). Stock Market Reactions to Contagious Animal Disease Outbreaks: An Event Study in Korean Foot-and-Mouth Disease Outbreaks. Agribusiness, 29(4), pp.455-468. https://doi.org/10.1002/agr.21346

Reuben, A. (2020). Why are there outbreaks in meat processing plants? BBC News. avaialble at: https:/www.bbc.com/news/53137613(accessed 3 June 2020)

Reuters. (2020). Sanderson Farms slaughterhouse worker tests positive for COVID-19. Reuters. available at: https://www.reuters.com/article/health-coronavirus-usa-sanderson-farmsidUSL1N2BG1QZ(accessed 23 March 2020)

Salisu, A., Ogbonna, A., \& Adediran, I. (2021). Stock-induced Google trends and the predictability of sectoral stock returns. Journal of Forecasting, 40(2), pp.327-345.

Seung-Pyo Jun, Hyoung Sun Yoo, \& San Choi. (2017). Ten years of research change using Google Trends_From the perspective of big data utilizations and applications | Elsevier Enhanced Reader. Technological Forcasting \& Social Change, pp.69-87. https://doi.org/10.1016/j.techfore.2017.11.009

Small, K. (2020). ConAgra plant in Marshall temporarily closes after 20 employees contract COVID-19. FOX 4 Kansas City WDAF-TV $\mid$ News, Weather, Sports. available at:https://fox4kc.com/tracking-coronavirus/marshall-missouri-conagra-plant-temporarilycloses-after-20-employees-contract-covid-19/(accessed 18 April 2020) 
Swamy, V., \& Dharani, M. (2019). Investor attention using the Google search volume indeximpact on stock returns. Review of Behavioral Fiance, Vol.11(No. 1), 56-70. https://doi.org/10.1108/RBF-04-2018-0033

Telford, T., \& Kindy, K. (2020). Inside Smithfield, JBS and Tysons Food meat plants, fears grew of employees working sick, without protective gear-The Washington Post. The Washington Post. available at: https://www.washingtonpost.com/business/2020/04/25/meat-workers-safety-jbssmithfield-tyson/(accessed 25 April 2020)

The White House. (2020). Executive Order on Delegating Authority Under the DPA with Respect to Food Supply Chain Resources During the National Emergency Caused by the Outbreak of COVID-19. The White House. avaialble at :https://www.whitehouse.gov/presidential-actions/executive-order-delegating-authoritydpa-respect-food-supply-chain-resources-national-emergency-caused-outbreak-covid19/( accessed 28 April 2020)

Thompson, J., Trejo-Pech, C., \& Pendell, D. (2019). Agribusiness value impacts from highly pathogenic avian influenza. Agricultural Finance Review, Vol. 79(No. 3). https://doi.org/10.1108/AFR-09-2018-0075

Tonsor, G., \& Schulz, L. (2020). COVID-19 Impacts on the Meat Processing Sector. CAST Commentary QTA2020-3, 15-16.

USDA. (2020). Meat, Poultry and Egg Product Inspection Directory. https://www.fsis.usda.gov/wps/portal/fsis/topics/inspection/mpi-directory 
USDA ERS. (2020). Meat and poultry plants employ about a third of U.S. food and beverage manufacturing employees. available at:http://www.ers.usda.gov/data-products/chartgallery/gallery/chart-detail/?chartId=58286(accessed 13 August 2020)

Waltenburg, M. A. (2020). Update: COVID-19 Among Workers in Meat and Poultry Processing Facilities - United States, April-May 2020. MMWR. Morbidity and Mortality Weekly Report, Vol. 69. https://doi.org/10.15585/mmwr.mm6927e2

WHO. (2020). Modes of transmission of virus causing COVID-19: Implications for IPC precaution recommendations. available at: https://www.who.int/newsroom/commentaries/detail/modes-of-transmission-of-virus-causing-covid-19implications-for-ipc-precaution-recommendations(accessed 29 March 2020)

Yahoo Finance. (n.d.). Yahoo Finance - Stock Market Live, Quotes, Business \& Finance News. Retrieved August 14, 2020, from https://finance.yahoo.com/

Yoshinaga, C., \& Rocco, F. (2020). Investor Attention: Can Google Search Volumes Predict Stock Returns? Brazilian Business Review, 523-539. http://dx.doi.org/10.15728/bbr.2020.17.5.3

${ }^{1}$ COVID-19 is an airborne respiratory illness transmitted from person to person through respiratory droplets within 1 meter of contact with an infected person (WHO, 2020). 
Title: The Impact of Supply Chain Disruptions on Stock Market Returns during Covid-19

Figures and Tables 


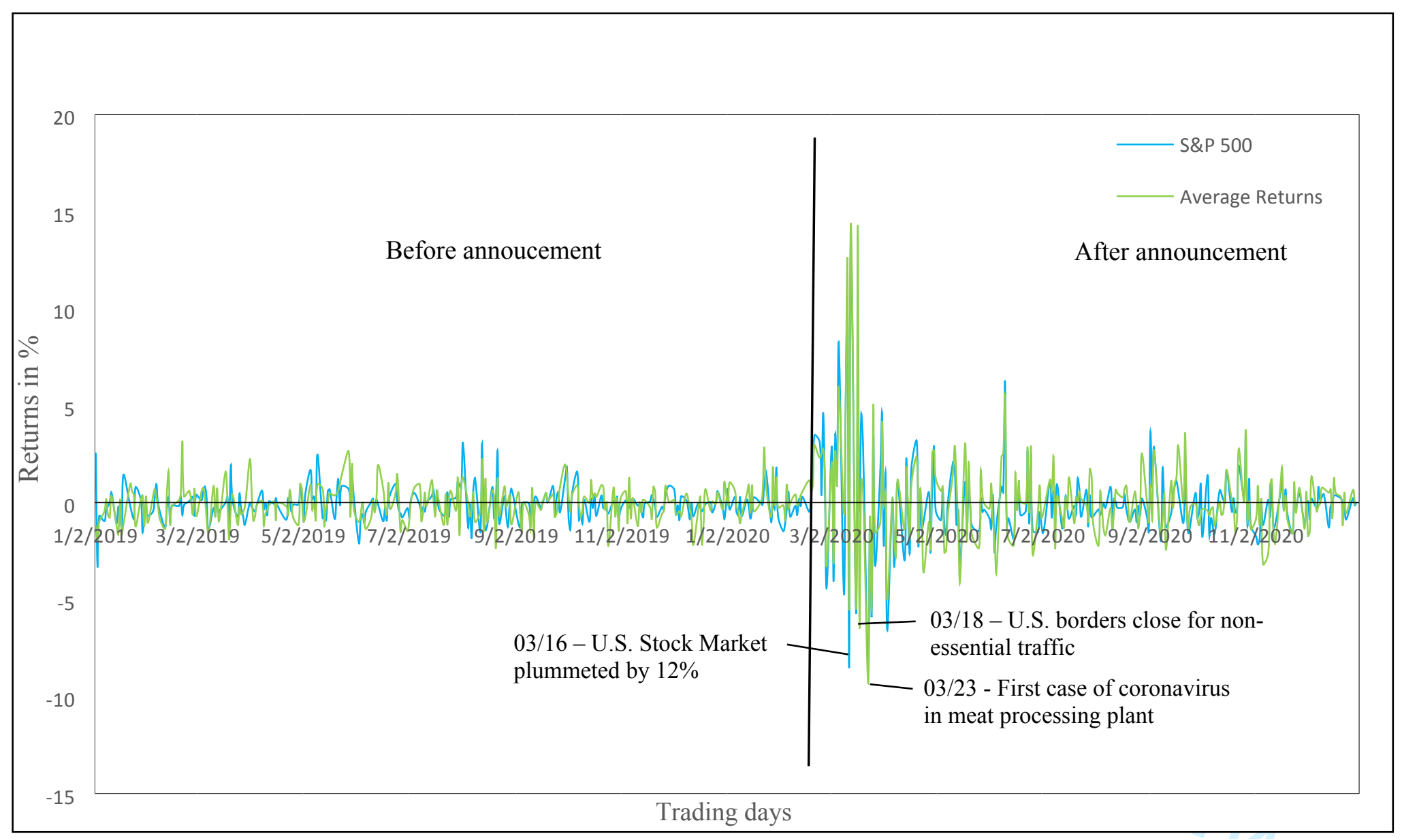

Source: Yahoo Finance and Mergent Online. Returns calculated by the authors. Note: the black line marks 3/11/2020.

Figure 1: The average stock returns of meat processing firms and S\&P 500 from January 2 to July 2, 2020 (before and after the W.H.O announcement of Covid-19 as a pandemic) 


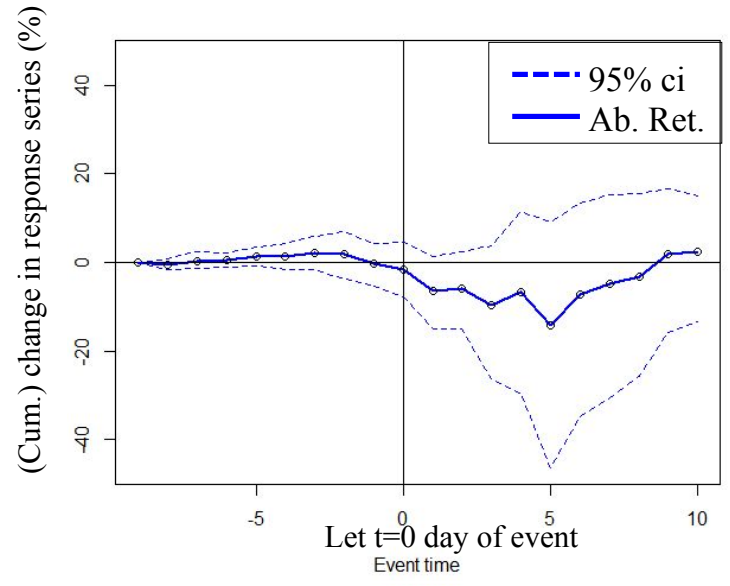

(a) Plot of the cumulative abnormal returns using market model

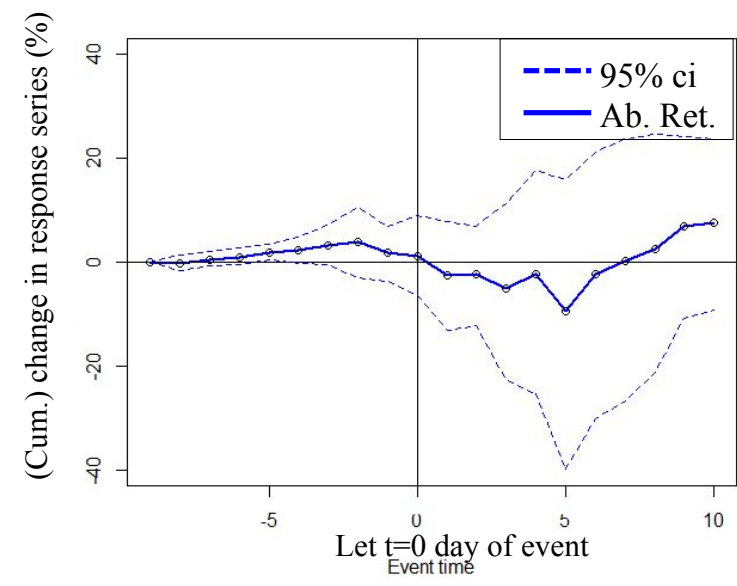

(b) Plot of the cumulative abnormal returns using augmented market model with Google trends ("Coronavirus")

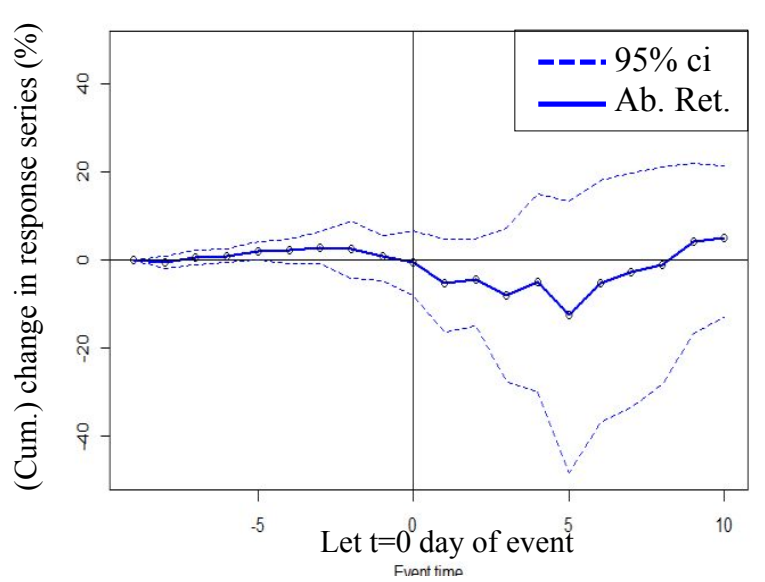

(c) Plot of the cumulative abnormal returns using augmented market model with Google trends ("Meat Processor") and financial beta

Figure 2 (a) - (c): Results from events study models for expected returns with and without Google trends for March 11 th

Note: Ab. Ret.: cumulative abnormal returns. 95\% C.I.: upper and lower bounds of the 95\% confidence interval 


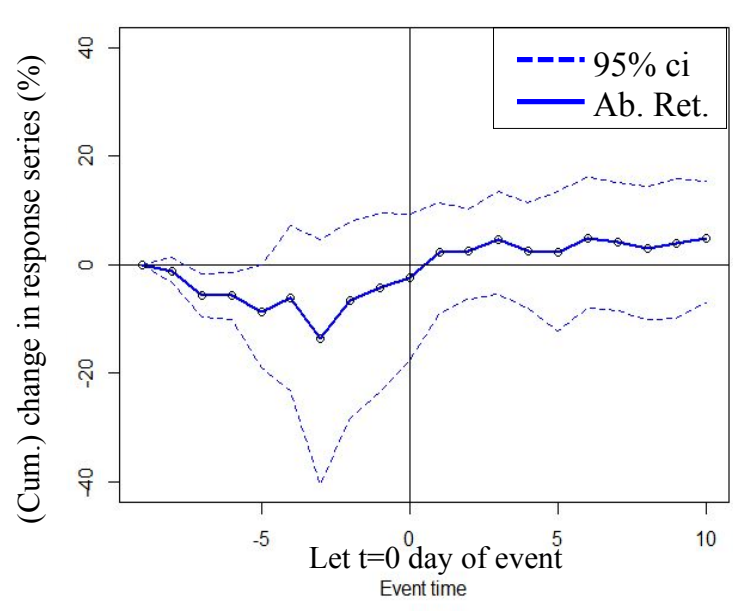

(a) Plot of the cumulative abnormal returns using market model

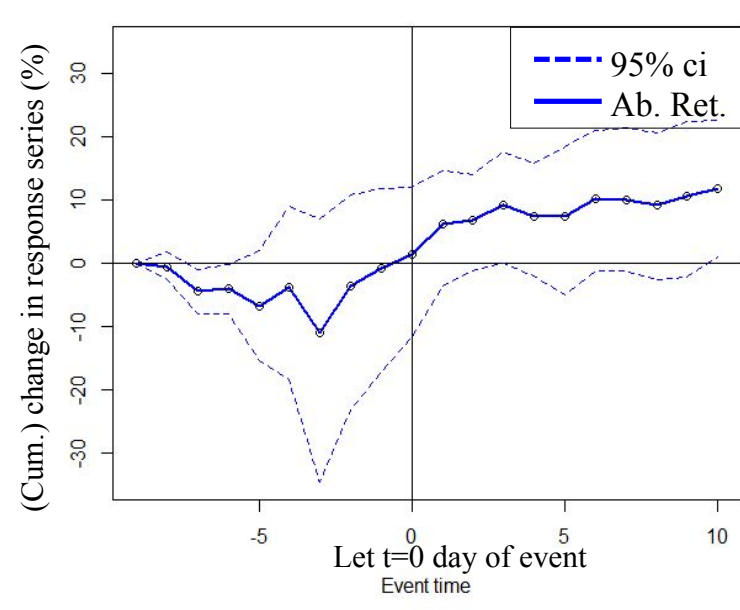

(b) Plot of the cumulative abnormal returns using augmented market model with Google trends ("Coronavirus")

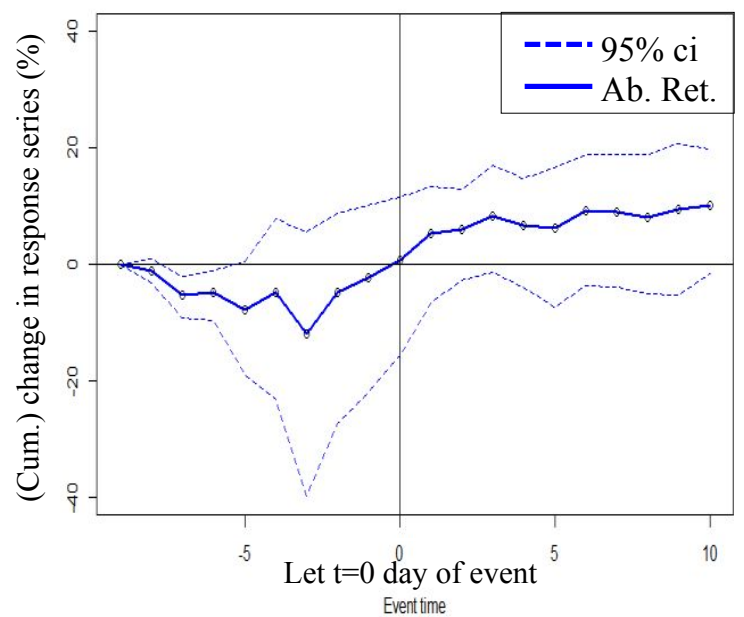

(c) Plot of the cumulative abnormal returns using augmented market model with Google trends ("Meat Processor") and financial beta

Figure 3 (a) - (c): Results from events study models for expected returns with and without Google trends for March $23^{\text {rd }}$

Note: Ab. Ret.: cumulative abnormal returns. 95\% C.I.: upper and lower bounds of the $95 \%$ confidence interval 


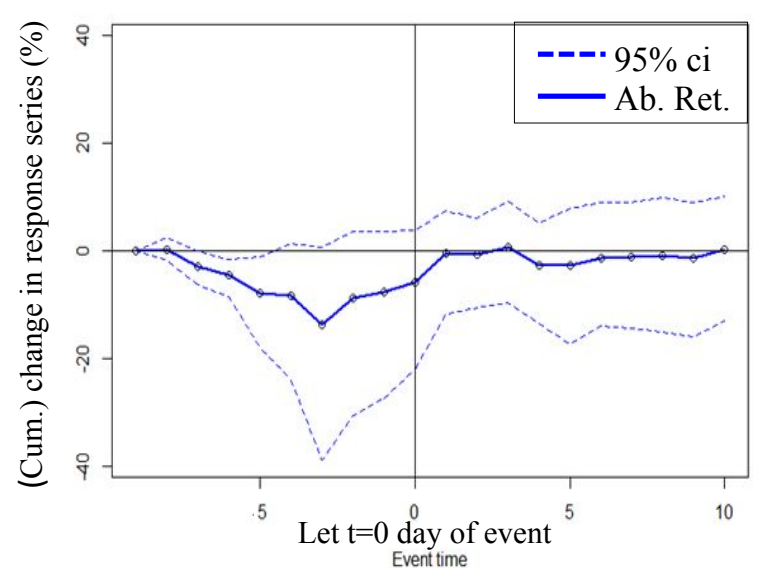

(a) Plot of the cumulative abnormal returns using market model

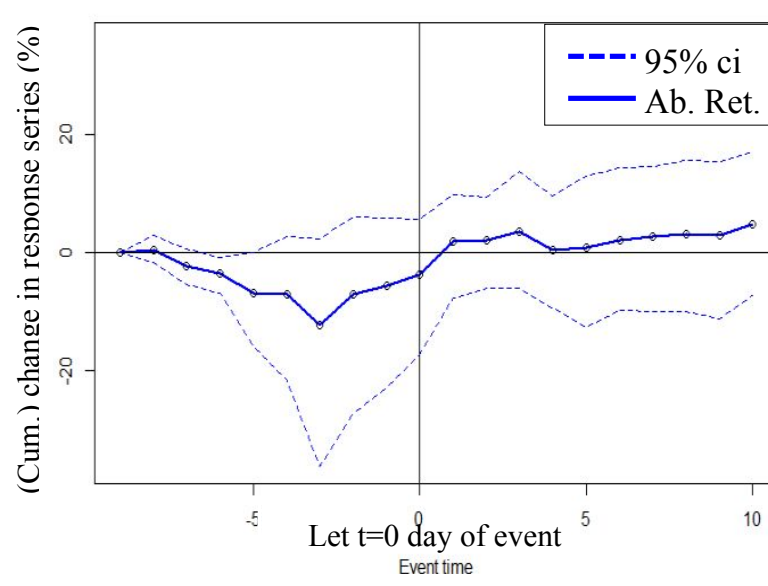

(b) Plot of the cumulative abnormal returns using augmented market model with Google trends ("Coronavirus")

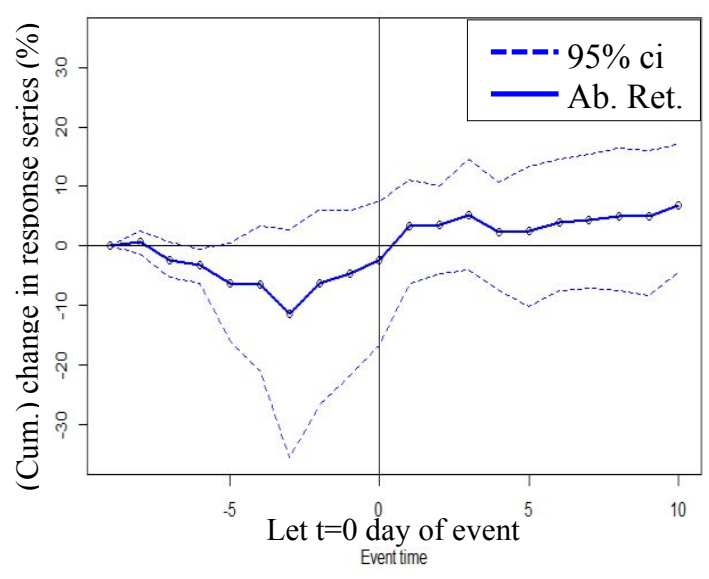

(c) Plot of the cumulative abnormal returns using augmented market model with Google trends ("Meat Processor") and financial beta

Figure 4 (a) - (c): Results from events study models for expected returns with and without Google trends for the $1^{\text {st }}$ cases of Covid-19 outbreak in individual meat processing plants

Note: $\mathrm{Ab}$. Ret.: cumulative abnormal returns. $95 \%$ C.I.: upper and lower bounds of the $95 \%$ confidence interval 


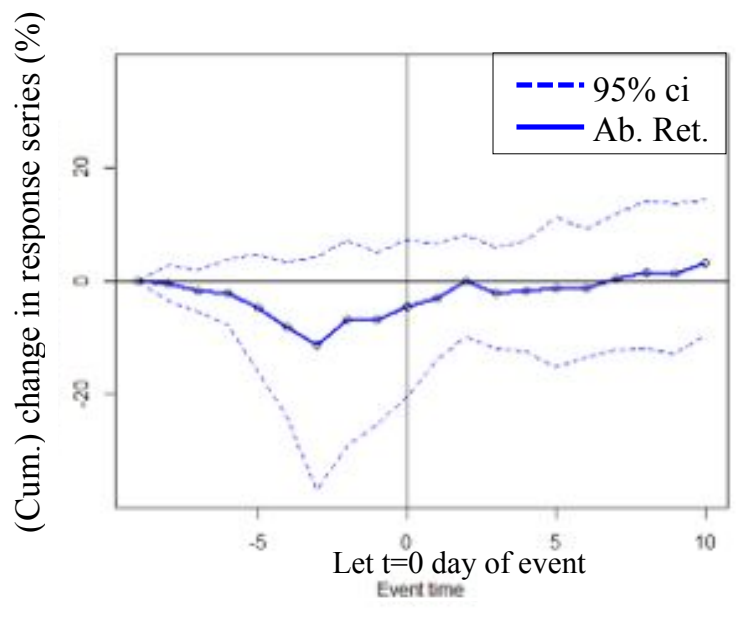

(a) Plot of the cumulative abnormal returns using market model

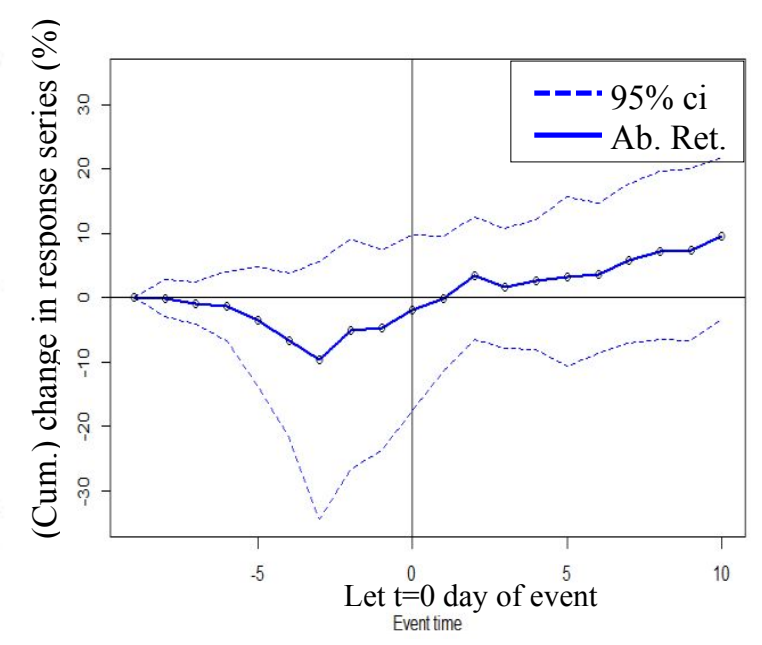

(b) Plot of the cumulative abnormal returns using augmented market model with Google trends ("Coronavirus")

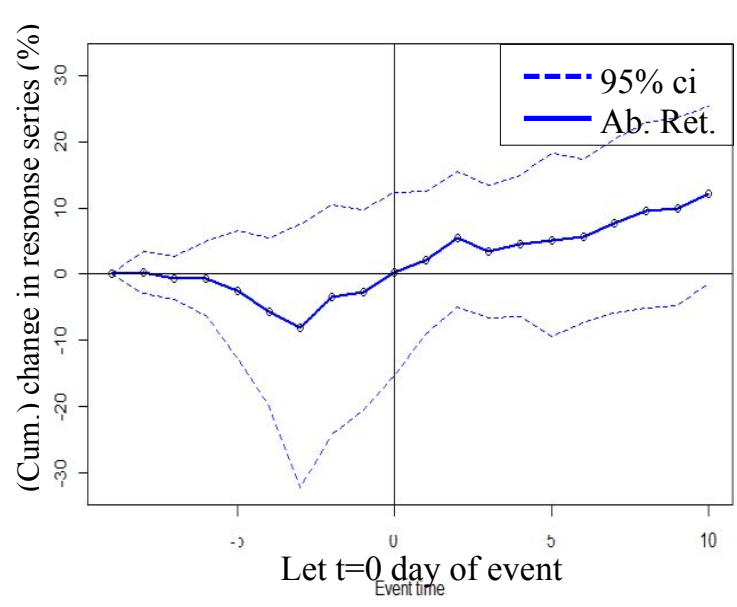

(c) Plot of the cumulative abnormal returns using augmented market model with Google trends ("Meat Processor") and financial beta

Figure 5 (a) - (c): Results from events study models for expected returns with and without Google trends for the Lockdown in various states Note: Ab. Ret.: cumulative abnormal returns. 95\% C.I.: upper and lower bounds of the 95\% confidence interval 
Table 1(a): Summary statistics of adjusted closed stock prices and returns in the U.S from January 2 to July 2, 2020

\begin{tabular}{|c|c|c|c|c|c|}
\hline & \multirow{2}{*}{ Stock Ticker } & \multicolumn{2}{|l|}{ Adj. close } & \multicolumn{2}{|c|}{ Returns (\%) } \\
\hline & & Mean & $\mathrm{SD}$ & Mean & $\mathrm{SD}$ \\
\hline Conagra Brands, Inc & $\mathrm{CAG}$ & 31.660 & 2.673 & 0.051 & 2.702 \\
\hline Hormel Foods Corporation & HRL & 46.524 & 2.018 & 0.073 & 2.400 \\
\hline The Kraft Heinz Company & $\mathrm{KHC}$ & 28.318 & 3.075 & 0.029 & 3.480 \\
\hline Mondelez International, Inc & MDLZ & 52.291 & 3.381 & -0.033 & 2.839 \\
\hline Pilgrim's Pride Corporation & & 21.841 & 4.360 & -0.519 & 3.857 \\
\hline Sanderson Farms, Inc. & SAFM & 133.266 & 15.096 & -0.351 & 3.525 \\
\hline Sysco Corporation & SYY & 59.850 & 14.145 & -0.341 & 5.620 \\
\hline Tyson Foods, Inc. & TSN & 66.941 & 11.792 & -0.332 & 3.962 \\
\hline Seaboard Corporation & SEB & 3310.179 & 474.327 & -0.292 & 2.962 \\
\hline The Chef's Warehouse, Inc. & CHEF & 21.532 & 11.511 & -0.818 & 12.095 \\
\hline Alco, Inc & $\mathrm{ALCO}$ & 31.619 & 3.451 & -0.089 & 4.600 \\
\hline Bridgford Foods Corporation & BRID & 19.147 & 3.562 & -0.307 & 6.582 \\
\hline MamaMancini's Holdings, Inc. & MMMB & 1.433 & 0.264 & 0.335 & 4.951 \\
\hline Cal-Maine Foods, Inc. & CALM & 40.281 & 3.068 & 0.046 & 3.064 \\
\hline S \& P 500 & ${ }^{\wedge} \mathrm{GSPC}$ & 2995.322 & 277.273 & -0.03177 & 2.915112 \\
\hline
\end{tabular}

Notes: SD is defined as the Standard Deviation. 
Table 1(b): Summary statistics of Google trends in the U.S from January 2 to July 2, 2020

\begin{tabular}{lccrc}
\hline & \multicolumn{2}{c}{ Index } & \multicolumn{3}{c}{ Percentage Change } \\
\cline { 2 - 5 } & Mean & SD & Mean & \multicolumn{1}{c}{ SD } \\
\hline Coronavirus & 22.685 & 23.771 & 4.193 & 26.641 \\
Meat Processor & 19.456 & 20.134 & -13.524 & 72.754 \\
\hline
\end{tabular}

Notes: SD is defined as the Standard Deviation. 
Table 2: Event details of selected meat processing firms

\begin{tabular}{|c|c|c|c|c|}
\hline Company & Stock & Dates & Events & References \\
\hline Sanderson Farms & NASDAQ & $3 / 23 / 2020$ & $\begin{array}{l}\text { Halt of poultry production for four weeks at one of its } \\
\text { plant at Moultrie, GA, after dozens of employees tested } \\
\text { positive }\end{array}$ & (Reuters 2020) \\
\hline Kraft Heinz Company & NASDAQ & $3 / 28 / 2020$ & $\begin{array}{l}\text { Kraft Foods plant in Springfield closes for deep } \\
\text { cleaning after two employees test positive for COVID- } \\
19\end{array}$ & (Staff 2020) \\
\hline TYSON Foods Inc & NYSE & $4 / 6 / 2020$ & $\begin{array}{l}\text { Pork production suspended in one of its plants in } \\
\text { Columbus Junction, Iowa }\end{array}$ & (Mickelson 2020) \\
\hline Hormel Foods & NYSE & $4 / 17 / 2020$ & Closure for two weeks of its meat plant at Rochelle, ILL & (Helfrich 2020) \\
\hline ConAgra & NYSE & $4 / 17 / 2020$ & $\begin{array}{l}\text { The frozen meal facility that closed its plant at Marshall, } \\
\text { Mo., last April } 17 \text { announces the plant will remain } \\
\text { closed till April } 27\end{array}$ & (Small 2020) \\
\hline Pilgrim's Pride & NASDAQ & $4 / 27 / 2020$ & $\begin{array}{l}\text { They didn't care about us:' N.C. poultry plant employee } \\
\text { with COVID-19 speaks out }\end{array}$ & (Kocher n.d.) \\
\hline Seaboard Corp & NYSE & $4 / 28 / 2020$ & Seaboard Triumph Foods worker dies of COVID-19 & (Butz, 2020) \\
\hline Alico, Inc & NasdaqGS & $3 / 23 / 2020$ & $\begin{array}{l}\text { We used the date of the first case of COVID-19 } \\
\text { outbreak in plants }\end{array}$ & \\
\hline Bridgford Foods Corporation & NASDAQ & $3 / 23 / 2020^{* *}$ & $\begin{array}{l}\text { We used the date of the first case of COVID- } 19 \\
\text { outbreak in plants }\end{array}$ & \\
\hline MamaMancini's Holdings, Inc. & Other OTC & $3 / 23 / 2020^{*}$ & We used the date from the event in Sanderson Farms & \\
\hline Cal-Maine Foods, Inc. & NASDAQ & $5 / 14 / 2020$ & $\begin{array}{l}\text { Flatonia Area Egg Facility Has Nine Employees Test } \\
\text { Positive for COVID-19 }\end{array}$ & (Behlen 2020) \\
\hline Chef's Warehouse Inc. & NasdaqGS & $3 / 23 / 2020^{* *}$ & $\begin{array}{l}\text { We used the date of the first case of COVID- } 19 \\
\text { outbreak in plants }\end{array}$ & \\
\hline Mondelez Intemational & NASDAQ & $4 / 17 / 2020^{*}$ & We used the date from the event in ConAgra & \\
\hline SYSCO Corp. & NYSE & $5 / 14 / 2020^{*}$ & We used the date from the event in Cal-Maine & \\
\hline
\end{tabular}

Notes: *We used the event of the first case of the COVID-19 outbreak.

**We used the event of nearest companies in the area with event date 
Table 3a: March $11^{\text {th }}$ event with Google Trends (“Coronavirus") (KP Test)

\begin{tabular}{|c|c|c|c|c|c|c|}
\hline \multicolumn{7}{|c|}{ Kolari and Pynnonen (2010) (KP) Test } \\
\hline Firm & $\operatorname{CAR}(0 ; 5)$ & $\operatorname{CAR}(-5 ; 0)$ & $\operatorname{CAR}(-5 ; 5)$ & $\operatorname{CAR}(0 ; 10)$ & $\operatorname{CAR}(-10 ; 0)$ & $\operatorname{CAR}(-10 ; 10)$ \\
\hline SYY & $-65.09 * * *$ & $-18.7 * * *$ & $-72.12 * * *$ & $-24.24 * * *$ & $-23.6 * * *$ & $-36.17 * * *$ \\
\hline ALCO & $-16.2 * * *$ & -5.07 & $-23.53 * * *$ & $9.84 * *$ & $-7.49 *$ & 0.09 . \\
\hline SAFM & 3.45 . & $15.5 * * *$ & $20.38 * * *$ & $21.93 * * *$ & $16.24 * * *$ & $39.6 * * *$ \\
\hline $\mathrm{KHC}$ & $8.16 * * *$ & -1.87 & $7.25 * *$ & 4.72 . & -1.04 . & 4.64 . \\
\hline CALM & $17.84 * * *$ & 4.78 . & $24.73 * * *$ & $21.27 * * *$ & 9.14 . & $32.52 * * *$ \\
\hline MDLZ & -2.95 . & 1.43 . & -0.49 . & -7.03 & -0.11 . & -6.11 . \\
\hline CAG & $6.74 *$ & 1.74 . & $9.9 *$ & 1. & 1.41 . & 3.83 . \\
\hline MMMB & $-29.38 * * *$ & $-26.3 * * *$ & $-48.75 * * *$ & $-25.59 * *$ & $-36.14 * * *$ & $-54.8 * * *$ \\
\hline SEB & $-3.98 * *$ & $-3.95 * *$ & $-7.6 * * *$ & -1.52 & $-5.56 * *$ & $-6.75 *$ \\
\hline HRL & $16.16 * * *$ & 0.72 . & $18.5 * * *$ & -0.14 . & -2.56 & -1.08 . \\
\hline PPC & 5.23 . & 1.55 . & 8.15 . & $16.06 * * *$ & 2.08 . & $19.5 * *$ \\
\hline BRID & $54.94 * * *$ & $29.06 *$ & $63.45 * * *$ & $59.94 * *$ & $39.37 *$ & $78.77^{* *}$ \\
\hline CHEF & $-185.07 * * *$ & $-33.44 * * *$ & $-206.16 * * *$ & $-70.65 * * *$ & $-42.49 * * *$ & $-100.78 * * *$ \\
\hline TSN & $-20.54 * * *$ & $-6.86 *$ & $-24.26 * * *$ & $14.52 * * *$ & -6.33 . & $11.33 *$ \\
\hline Ptf CAR: & $-15.05 * * *$ & -2.96 & $-16.47 * * *$ & 1.44 . & -4.08 & -1.1 \\
\hline
\end{tabular}

$* * * \mathrm{p}$-value $<.01, * * \mathrm{p}$-value $<.05, * \mathrm{p}$-value $<.1$
Table 3b: March $11^{\text {th }}$ event with Google Trends ("Coronavirus") (GRANK Test)

\begin{tabular}{|c|c|c|c|c|c|c|}
\hline \multicolumn{7}{|c|}{ Kolari and Pynnonen (2011) Generalized Rank Test (GRANK) } \\
\hline Firm & $\operatorname{CAR}(0 ; 5)$ & $\operatorname{CAR}(-5 ; 0)$ & $\operatorname{CAR}(-5 ; 5)$ & $\operatorname{CAR}(0 ; 10)$ & $\operatorname{CAR}(-10 ; 0)$ & $\operatorname{CAR}(-10 ; 10)$ \\
\hline SYY & $-65.09 * * *$ & $-18.7 * * *$ & $-72.12 * * *$ & $-24.24 * * *$ & $-23.6 * * *$ & $-36.17 * * *$ \\
\hline ALCO & $-16.2 * * *$ & -5.07 & $-23.53 * * *$ & $9.84 * *$ & $-7.49 *$ & 0.09 . \\
\hline SAFM & 3.45 . & $15.5 * * *$ & $20.38 * * *$ & $21.93 * * *$ & $16.24 * *$ & $39.6 * * *$ \\
\hline $\mathrm{KHC}$ & $8.16 * * *$ & -1.87 & $7.25 *$ & 4.72 . & -1.04 & 4.64 . \\
\hline CALM & $17.84 * * *$ & 4.78 . & $24.73 * * *$ & $21.27 * * *$ & 9.14 . & $32.52 * * *$ \\
\hline MDLZ & -2.95 & 1.43 . & -0.49 . & -7.03 & -0.11 & -6.11 \\
\hline CAG & $6.74 *$ & 1.74 . & $9.9 *$ & 1. & 1.41 . & 3.83 . \\
\hline MMMB & $-29.38 * * *$ & $-26.3 * *$ & $-48.75 * * *$ & $-25.59 *$ & $-36.14 * * *$ & $-54.8 * * *$ \\
\hline SEB & $-3.98 * *$ & $-3.95 *$ & $-7.6 * * *$ & -1.52 . & $-5.56 * *$ & $-6.75 *$ \\
\hline HRL & $16.16 * * *$ & 0.72 . & $18.5 * * *$ & -0.14 . & -2.56 . & -1.08 \\
\hline PPC & 5.23 . & 1.55 . & 8.15 . & $16.06 * * *$ & 2.08 . & $19.5 * *$ \\
\hline BRID & $54.94 * * *$ & 29.06 . & $63.45 * *$ & $59.94 * *$ & 39.37 . & $78.77 * *$ \\
\hline CHEF & $-185.07 * * *$ & $-33.44 * * *$ & $-206.16 * * *$ & $-70.65 * * *$ & $-42.49 * * *$ & $-100.78 * * *$ \\
\hline TSN & $-20.54 * * *$ & $-6.86 *$ & $-24.26 * * *$ & $14.52 * * *$ & -6.33 . & $11.33 *$ \\
\hline Ptf CARs & $-11.69 * * *$ & -2.82 . & $-13.04 * * *$ & $6.52 * *$ & -3.98 & 4.01. \\
\hline
\end{tabular}


Table 3c: March $11^{\text {th }}$ event with Google Trends term ("Meat processor") and financial beta (KP Test)

\begin{tabular}{lcccccc}
\hline March 11th, Kolari and Pynnonen $(2010)$ & $(\mathrm{KP})$ Test with Google Trends and Beta \\
\hline Firm & CAR $(0 ; 5)$ & CAR $(-5 ; 0)$ & CAR $(-5 ; 5)$ & CAR $(0 ; 10)$ & CAR $(-10 ; 0)$ & CAR $(-10 ; 10)$ \\
\hline SYY & $-79.21 * * *$ & $-24.74 * * *$ & $-90.69 * * *$ & $-50.15 * * *$ & $-34.81 * *$ & $-71.7 * * *$ \\
ALCO & $-15.38 * * *$ & -4.68 & $-22.37 * * *$ & $11.96 * *$ & -6.8 & 2.85 \\
SAFM & 5.96 & $16.36 * * *$ & $23.81 * * *$ & $26.41 * * *$ & $18.32 * *$ & $46.23 * * *$ \\
KHC & $14.24 * * *$ & 0.82. & $15.51 * * *$ & $17.16 * * *$ & 3.85 & $21.46 * * *$ \\
CALM & $31.25 * * *$ & $10.19 * *$ & $43.32 * * *$ & $51.55 * * *$ & $19.8 * * *$ & $73.23 * * *$ \\
MDLZ & $-34.62 * * *$ & $-12.26 * * *$ & $-42.97 * * *$ & $-70.88 * * *$ & $-24.98 * * *$ & $-91.95 * * *$ \\
CAG & -3.86. & -2.79 & -4.7 & $-23.23 * * *$ & -6.89. & $-28.16 * * *$ \\
MMMB & $-67.36 * * *$ & $-44.56 * * *$ & $-98.16 * * *$ & $-90.26 * * *$ & $-66.31 * * *$ & $-142.82 * * *$ \\
SEB & $13.03 * * *$ & $3.53 *$ & $15.23 * * *$ & $32.3 * * *$ & $7.97 * * *$ & $38.95 * * *$ \\
HRL & $9 * * *$ & -2.6 & $9.13 * * *$ & $-13.26 * * *$ & $-8.3 * * *$ & $-18.81 * * *$ \\
PPC & -5.58. & -4.03 & -5.82. & -3.37 & -6.37. & -5.94 \\
BRID & $136.2 * * *$ & $61.76 * * *$ & $177.61 * * *$ & $255.02 * * *$ & $103.27 * * *$ & $337.94 * * *$ \\
CHEF & $-171.24 * * *$ & $-27.24 * * *$ & $-188.05 * * *$ & $-46.49 * * *$ & $-31.61 * * *$ & $-67.67 * * *$ \\
TSN & $-23.79 * * *$ & $-8.71 * *$ & $-28.79 * * *$ & 6.49 & $-8.98 *$ & 1.22. \\
Ptf CARs & $-10.52 * * *$ & -2.74 & $-10.92 * * *$ & $12.14 * * *$ & -3.06. & $11.42 * * *$ \\
\hline
\end{tabular}

*** $\mathrm{p}$-value $<.01,{ }^{* *} \mathrm{p}$-value $<.05, * \mathrm{p}$-value $<.1$
Table 3d: March 11 th event with Google Trends term ("Meat processor") and financial beta (GRANK Test)

\begin{tabular}{lcccccc}
\hline \multicolumn{7}{l}{ March 11th, Generalized Rank Test (GRANK) with Google Trends and Beta } \\
\hline Firm & CAR $(0 ; 5)$ & CAR $(-5 ; 0)$ & CAR $(-5 ; 5)$ & CAR $(0 ; 10)$ & CAR $(-10 ; 0)$ & CAR $(-10 ; 10)$ \\
\hline SYY & $-79.21 * * *$ & $-24.74 * * *$ & $-90.69 * * *$ & $-50.15 * * *$ & $-34.81 * * *$ & $-71.7 * * *$ \\
ALCO & $-15.38 * * *$ & -4.68 & $-22.37 * * *$ & $11.96 * *$ & -6.8 & 2.85 \\
SAFM & 5.96. & $16.36 * * *$ & $23.81 * * *$ & $26.41 * * *$ & $18.32 * *$ & $46.23 * * *$ \\
KHC & $14.24 * * *$ & 0.82. & $15.51 * * *$ & $17.16 * * *$ & 3.85 & $21.46 * * *$ \\
CALM & $31.25 * * *$ & $10.19 * *$ & $43.32 * * *$ & $51.55 * * *$ & $19.8 * * *$ & $73.23 * * *$ \\
MDLZ & $-34.62 * * *$ & $-12.26 * * *$ & $-42.97 * * *$ & $-70.88 * * *$ & $-24.98 * * *$ & $-91.95 * * *$ \\
CAG & -3.86. & -2.79 & -4.7. & $-23.23 * * *$ & -6.89. & $-28.16 * * *$ \\
MMMB & $-67.36 * * *$ & $-44.56 * * *$ & $-98.16 * * *$ & $-90.26 * * *$ & $-66.31 * * *$ & $-142.8 * * *$ \\
SEB & $13.03 * * *$ & $3.53 *$ & $15.23 * * *$ & $32.3 * * *$ & $7.97 * * *$ & $38.95 * * *$ \\
HRL & $9 * * *$ & -2.6 & $9.13 * * *$ & $-13.26 * * *$ & $-8.3 * * *$ & $-18.81 * * *$ \\
PPC & -5.58. & -4.03 & -5.82. & -3.37. & -6.37. & -5.94. \\
BRID & $136.2 * * *$ & $61.76 * * *$ & $177.61 * * *$ & $255.02 * * *$ & $103.27 * * *$ & $337.94 * * *$ \\
CHEF & $-171.24 * * *$ & $-27.24 * * *$ & $-188.05 * * *$ & $-46.49 * * *$ & $-31.61 * * *$ & $-67.67 * * *$ \\
TSN & $-23.79 * * *$ & $-8.71 * *$ & $-28.79 * * *$ & 6.49 & $-8.98 *$ & 1.22. \\
Ptf CARs & $-10.52 * * *$ & -2.74 & $-10.92 * * *$ & $12.14 * * *$ & -3.06. & $11.42 * * *$ \\
\hline
\end{tabular}

$* * *$ p-value $<.01, * *$ p-value $<.05, *$ p-value $<.1$ 
Table 3e: March $11^{\text {th }}$ event market model (KP Test)

\begin{tabular}{lcccccc}
\hline Kolari and Pynnonen $(2010)(\mathrm{KP})$ Test \\
\hline Firm & CAR $(0 ; 5)$ & CAR $(-5 ; 0)$ & CAR $(-5 ; 5)$ & CAR $(0 ; 10)$ & CAR $(-10 ; 0)$ & CAR $(-10 ; 10)$ \\
\hline SYY & $-50.83 * * *$ & $-12.55 * * *$ & $-56 * * *$ & $-16.09 * * *$ & $-16.26 * * *$ & $-24.97 * * *$ \\
ALCO & -3.72. & 0.95. & $-8.48 *$ & $19.67 * * *$ & 1.02. & $14.98 * *$ \\
SAFM & 0.57. & $10.97 * *$ & $13.23 * *$ & $14.31 * *$ & 7.76. & $23.75 * * *$ \\
KHC & $16.73 * * *$ & 1.64. & $16.85 * * *$ & $10.41 * * *$ & 3.51. & $12.4 * *$ \\
CALM & $22.02 * * *$ & 5.27. & $27.96 * * *$ & $21.84 * * *$ & 8.77. & $31.28 * * *$ \\
MDLZ & 1.87. & 4.56. & 6.21. & -2.27. & 4.65. & 2.16. \\
CAG & $16.21 * * *$ & 5.97. & $21.02 * * *$ & 8.6. & 7.52. & $14.95 * *$ \\
MMMB & 7.85. & -5.67. & -0.81. & 7.65. & -5.52. & -0.86. \\
SEB & $3.82 *$ & -1.43. & 0.38. & 2.77. & -2.7. & -1.94 \\
HRL & $28.2 * * *$ & $7.44 * * *$ & $34.09 * * *$ & $10.95 * * *$ & $7.58 * *$ & $16.98 * * *$ \\
PPC & -1.17. & -4.37. & -2.87. & 6.42. & -8.06. & 1.04. \\
BRID & 16. & 7.49. & 12.53. & 18.77. & 4.31. & 12.13. \\
CHEF & $-171.65 * * *$ & $-26.76 * * *$ & $-189.55 * * *$ & $-58.18 * * *$ & $-32.18 * * *$ & $-81.5 * * *$ \\
TSN & $-16.71 * * *$ & $-6.57 *$ & $-21.35 * * *$ & $15.88 * * *$ & -6.47. & 11.34. \\
Ptf CAR: & $-9.34 * * *$ & -0.93. & $-10.48 * * *$ & 4.34. & -1.86. & 2.27. \\
\hline
\end{tabular}

$* * * \mathrm{p}$-value $<.01,{ }^{* *} \mathrm{p}$-value $<.05, * \mathrm{p}$-value $<.1$
Table 3f: March $11^{\text {th }}$ event market model

\begin{tabular}{|c|c|c|c|c|c|c|}
\hline \multicolumn{7}{|c|}{ Kolari and Pynnonen (2011) Generalized Rank Test (GRANK) } \\
\hline Firm & $\operatorname{CAR}(0 ; 5)$ & $\operatorname{CAR}(-5 ; 0)$ & $\operatorname{CAR}(-5 ; 5)$ & $\operatorname{CAR}(0 ; 10)$ & $\operatorname{CAR}(-10 ; 0)$ & $\operatorname{CAR}(-10 ; 10)$ \\
\hline SYY & $-50.83 * * *$ & $-12.55 * * *$ & $-56 * * *$ & $-16.09 * *$ & $-16.26 * *$ & $-24.97 * * *$ \\
\hline ALCO & -3.72 & 0.95 . & $-8.48 *$ & $19.67 * * *$ & 1.02 . & $14.98 * *$ \\
\hline SAFM & 0.57 . & $10.97 * *$ & $13.23 * *$ & $14.31 * *$ & 7.76 . & $23.75 * *$ \\
\hline $\mathrm{KHC}$ & $16.73 * * *$ & 1.64. & $16.85 * * *$ & $10.41 * *$ & 3.51 . & $12.4^{* *}$ \\
\hline CALM & $22.02 * * *$ & 5.27 . & $27.96 * * *$ & $21.84 * * *$ & 8.77 . & $31.28 * * *$ \\
\hline MDLZ & 1.87. & 4.56. & 6.21. & -2.27 & 4.65 . & 2.16 \\
\hline $\mathrm{CAG}$ & $16.21 * * *$ & 5.97. & $21.02 * * *$ & 8.6 . & 7.52 . & $14.95 *$ \\
\hline MMMB & 7.85 & -5.67 & -0.81 & 7.65. & -5.52 & -0.86 \\
\hline SEB & $3.82 *$ & -1.43 & 0.38 . & 2.77 . & -2.7 & -1.94 . \\
\hline HRL & $28.2 * * *$ & $7.44 * * *$ & $34.09 * * *$ & $10.95 * * *$ & $7.58 * *$ & $16.98 * * *$ \\
\hline PPC & -1.17 & -4.37 & -2.87 & 6.42 & -8.06 & 1.04 \\
\hline BRID & 16. & 7.49 & 12.53 & 18.77. & 4.31 . & 12.13. \\
\hline CHEF & $-171.65 * * *$ & $-26.76 * * *$ & $-189.55 * * *$ & $-58.18 * * *$ & $-32.18 * * *$ & $-81.5 * * *$ \\
\hline TSN & $-16.71 * * *$ & $-6.57 *$ & $-21.35 * * *$ & $15.88 * * *$ & -6.47 & 11.34 \\
\hline Ptf CARs & $-5.79 * * *$ & -0.6 & $-6.71 * *$ & $9.74 * * *$ & -1.42 . & $7.99 * *$ \\
\hline
\end{tabular}

$* * *$ p-value $<.01, * *$ p-value $<.05, *$ p-value $<.1$ 
Table 4a: March $23^{\text {rd }}$ event with Google Trends term ("Coronavirus") (KP Test)

\begin{tabular}{lcccccc}
\hline Kolari and Pynnonen $(2010)(\mathrm{KP})$ Test & & & \\
\hline Firm & CAR $(0 ; 5)$ & CAR $(-5 ; 0)$ & CAR $(-5 ; 5)$ & CAR $(0 ; 10)$ & CAR $(-10 ; 0)$ & CAR $(-10 ; 10)$ \\
\hline SYY & $25.5 * * *$ & $-16.83 * * *$ & 4.59 & $25.25 * * *$ & $-47.6 * * *$ & $-26.42 * * *$ \\
ALCO & -2.23 & -2.3 & 1.08 & -0.42 & -4.04 & 1.14 \\
SAFM & -6.96 & $22.88 * * *$ & $11.56 *$ & -9.75 & $23.94 * * *$ & 9.82. \\
KHC & $8.64 * *$ & -2.24. & $11.52 * *$ & $13.19 * *$ & -1.92. & $16.39 * *$ \\
CALM & 3.24. & $17.66 * * *$ & $22.21 * * *$ & 1.06. & $17.97 * * *$ & $20.33 * *$ \\
MDLZ & $6.42 * *$ & -5.22. & 2.28. & 6.41. & $-8.12 *$ & -0.64 \\
CAG & 3.61. & $16.56 * * *$ & $19.3 * * *$ & $15.21 * *$ & $10.14 *$ & $24.47 * * *$ \\
MMMB & 8.19. & -14.41. & 0.03. & $25.56 *$ & $-43.6 * * *$ & -11.8 \\
SEB & 2.65. & 2.46. & 0.84. & 0.51. & -4.25. & $-8.02 *$ \\
HRL & -4.33. & $12.67 * * *$ & $12.78 * * *$ & -1.32. & $14.57 * * *$ & $17.69 * * *$ \\
PPC & -3.84. & $17.07 * * *$ & $10.1 *$ & -3.79. & $19.98 * * *$ & $13.05 *$ \\
BRD & 9.91. & $54.14 * * *$ & $61.88 * * *$ & 10.93. & $58.94 * * *$ & $67.71 * *$ \\
CHEF & $45.02 * * *$ & $-84.67 * * *$ & $-60.67 * * *$ & $55.92 * * *$ & $-118.43 * * *$ & $-83.52 * * *$ \\
TSN & $6.33 *$ & $19.04 * * *$ & $16.66 * * *$ & 2.92. & 4.71. & -1.09 \\
Ptf CARs & $7.3 * * *$ & 2.63 & $8.15 * * *$ & $10.12 * * *$ & $-5.55 * *$ & 2.79. \\
\hline
\end{tabular}

$* * *$ p-value $<.01,{ }^{* *}$ p-value $<.05,{ }^{*}$ p-value $<.1$
Table 4b: March $23^{\text {rd }}$ event with Google Trends term ("Coronavirus") (GRANK Test)

\begin{tabular}{|c|c|c|c|c|c|c|}
\hline \multicolumn{7}{|c|}{ Kolari and Pynnonen (2011) Generalized Rank Test (GRANK) } \\
\hline Firm & $\operatorname{CAR}(0 ; 5)$ & $\operatorname{CAR}(-5 ; 0)$ & $\operatorname{CAR}(-5 ; 5)$ & $\operatorname{CAR}(0 ; 10)$ & $\operatorname{CAR}(-10 ; 0)$ & $\operatorname{CAR}(-10 ; 10)$ \\
\hline SYY & $25.5 * * *$ & $-16.8 * * *$ & 4.59 & $25.25 * * *$ & $-47.6 * * *$ & $-26.42 * * *$ \\
\hline ALCO & -2.23 . & -2.3 . & 1.08 . & -0.42 . & -4.04 . & 1.14 . \\
\hline SAFM & -6.96 & $22.88 * * *$ & $11.56 *$ & -9.75 . & $23.94 * * *$ & 9.82 . \\
\hline $\mathrm{KHC}$ & $8.64 * *$ & -2.24 . & $11.52 *$ & $13.19 * *$ & -1.92 . & $16.39 * *$ \\
\hline CALM & 3.24 . & $17.66^{* * *}$ & $22.21 * * *$ & 1.06 . & $17.97^{* * *}$ & $20.33 * *$ \\
\hline MDLZ & $6.42 *$ & -5.22 . & 2.28 . & 6.41 . & $-8.12 *$ & -0.64 . \\
\hline CAG & 3.61 . & $16.56 * * *$ & $19.3 * * *$ & $15.21 * *$ & $10.14 *$ & $24.47 * * *$ \\
\hline MMMB & 8.19 . & -14.4 . & 0.03 . & $25.56 *$ & $-43.6 * * *$ & -11.8 . \\
\hline SEB & 2.65 . & 2.46 . & 0.84 . & 0.51 . & -4.25 . & $-8.02 *$ \\
\hline HRL & -4.33 & $12.67^{* * *}$ & $12.78 * * *$ & -1.32 . & $14.57^{* * *}$ & $17.69 * * *$ \\
\hline PPC & -3.84 & $17.07 * * *$ & $10.1 *$ & -3.79 . & $19.98 * * *$ & $13.05 *$ \\
\hline BRID & 9.91 . & $54.14 * * *$ & $61.88 * * *$ & 10.93 . & $58.94 * * *$ & $67.71 * *$ \\
\hline CHEF & $45.02 * * *$ & $-84.7 * * *$ & $-60.67 * * *$ & $55.92 * * *$ & $-118.43 * * *$ & $-83.52 * * *$ \\
\hline TSN & $6.33 *$ & $19.04 * * *$ & $16.66 * * *$ & 2.92 . & 4.71 . & -1.09 . \\
\hline Ptf CARs & $8.9 * * *$ & $6.63 * * *$ & $13.52 * * *$ & $12.03 * * *$ & -1.08 & $8.95 * * *$ \\
\hline
\end{tabular}

$* * *$ p-value $<.01, * *$ p-value $<.05, *$ p-value $<.1$ 
Table 4c: March 23 $3^{\text {rd }}$ event with Google Trends term ("Meat processor") and financial beta (KP Test)

\begin{tabular}{|c|c|c|c|c|c|c|}
\hline \multicolumn{7}{|c|}{ March 23rd, Kolari and Pynnonen (2011) with Google Trends and Beta } \\
\hline Firm & $\operatorname{CAR}(0 ; 5)$ & $\operatorname{CAR}(-5 ; 0)$ & $\operatorname{CAR}(-5 ; 5)$ & $\operatorname{CAR}(0 ; 10)$ & $\operatorname{CAR}(-10 ; 0)$ & $\operatorname{CAR}(-10 ; 10)$ \\
\hline$\overline{\text { SYY }}$ & $21.36 * * *$ & $-27.04 * * *$ & -7.61 & $16.39 * * *$ & $-61.1 * * *$ & $-46.64 * * *$ \\
\hline ALCO & 0.14 & -3.55 & 2.41 . & 3.02 . & -5.72 . & 3.12 . \\
\hline SAFM & $-16.5 * * *$ & $15.22 * * *$ & -5.39 & $-27.7 * * *$ & $12.45 *$ & $-19.34 * *$ \\
\hline $\mathrm{KHC}$ & $9.92 * *$ & -0.22 . & $14.09 * *$ & $15.44 * *$ & 0.48 . & $20.3 * *$ \\
\hline CALM & $16.61 * * *$ & $28.61 * * *$ & $43.23 * * *$ & $24.19 * * *$ & $31.87 * * *$ & $54.07 * * *$ \\
\hline MDLZ & $-22.1 * * *$ & $-31.8 * * *$ & $-47.69 * * *$ & $-45.36 * * *$ & $-44.35 * * *$ & $-83.53 * * *$ \\
\hline $\mathrm{CAG}$ & $-11.1 * *$ & 4.2 . & -6.84 & $-12.07 * *$ & -7.94 & $-19.98 * *$ \\
\hline MMMB & 14.86 & 2.42 . & 20.96 . & $40.68 * * *$ & -20.46 & 23.9 . \\
\hline SEB & $18.46 * * *$ & $22.5 * * *$ & $32.87 * * *$ & $30.54 * * *$ & $22.77 * * *$ & $45.22 * * *$ \\
\hline HRL & $-9.62 * * *$ & 2.58 . & -0.75 & $-12.16 * *$ & 0.88 . & -4.99 . \\
\hline PPC & -0.03 & $29.18 * * *$ & $21.64 * * *$ & 3.75 . & $34.37 * * *$ & $30.61 * * *$ \\
\hline BRID & $116.7 * * *$ & $112.24 * * *$ & $209.8 * * *$ & $190.49 * * *$ & $133.99 * * *$ & $305.31 * * *$ \\
\hline CHEF & $53.53 * * *$ & $-67.19 * * *$ & $-37.46 * * *$ & $73.96 * * *$ & $-94.36 * * *$ & $-44.21 * * *$ \\
\hline TSN & 1.04 & $24.17 * * *$ & $14.52 * * *$ & -5.01 & $10.59 * *$ & -5.1. \\
\hline Ptf CARs & $15.54 * * *$ & $11.83 * * *$ & $23.52 * * *$ & $23.24 * * *$ & $5.28 * *$ & $24.67 * * *$ \\
\hline
\end{tabular}

$* * *$ p-value $<.01, * *$ p-value $<.05, *$ p-value $<.1$
Table 4d: March 23 $3^{\text {rd }}$ event with Google Trends term ("Meat Processor") and financial beta (GRANK Test)

\begin{tabular}{|c|c|c|c|c|c|c|}
\hline \multicolumn{7}{|c|}{ March 23rd, Generalized Rank Test (GRANK) with Google Trends and Beta } \\
\hline Firm & $\operatorname{CAR}(0 ; 5)$ & $\operatorname{CAR}(-5 ; 0)$ & $\operatorname{CAR}(-5 ; 5)$ & $\operatorname{CAR}(0 ; 10)$ & $\operatorname{CAR}(-10 ; 0)$ & $\operatorname{CAR}(-10 ; 10)$ \\
\hline SYY & $21.36 * * *$ & $-27.04 * * *$ & -7.61 & $16.39 * * *$ & $-61.1 * * *$ & $-46.64 * * *$ \\
\hline LCO & 0.14 & -3.55 . & 2.41 . & 3.02 . & -5.72 . & 3.12 . \\
\hline AFM & $-16.5 * * *$ & $15.22 * * *$ & -5.39 . & $17.7 * * *$ & $12.45 *$ & $-19.34 * *$ \\
\hline $\mathrm{HC}$ & $9.92 * *$ & -0.22 . & $14.09 * *$ & $15.44 * *$ & 0.48 & $20.3 * *$ \\
\hline ALM & $16.61 * * *$ & $28.61 * * *$ & $43.23 * * *$ & $24.19 * * *$ & $31.87 * * *$ & $54.07 * * *$ \\
\hline MDLZ & $-22.1 * * *$ & $-31.8 * * *$ & $-47.69 * * *$ & $-45.36 * * *$ & $-44.35 * * *$ & $-83.53 * * *$ \\
\hline$A G$ & $-11.1 * *$ & 4.2 . & -6.84 . & $-12.07 * *$ & -7.94 & $-19.98 * *$ \\
\hline $\mathrm{MMM}$ & 14.86 . & 2.42 . & 20.96 . & $40.68 * * *$ & -20.46 . & 23.9. \\
\hline SEB & $18.46^{* * *}$ & $22.5 * * *$ & $32.87 * * *$ & $30.54 * * *$ & $22.77 * * *$ & $45.22 * * *$ \\
\hline HRL & $-9.62 * * *$ & 2.58 . & -0.75 & $-12.16 * *$ & 0.88 . & -4.99 . \\
\hline PPC & -0.03 & $29.18 * * *$ & $21.64 * * *$ & 3.75 . & $34.37^{* * *}$ & $30.61 * * *$ \\
\hline BRID & $116.7 * * *$ & $112.24 * * *$ & $209.8 * * *$ & $190.49 * * *$ & $133.99 * * *$ & $305.31 * * *$ \\
\hline CHEF & $53.53 * * *$ & $-67.19 * * *$ & $-37.46 * * *$ & $73.96 * * *$ & $-94.36 * * *$ & $-44.21 * * *$ \\
\hline TSN & 1.04 & $24.17 * * *$ & $14.52 * * *$ & -5.01 & $10.59 * *$ & -5.1 . \\
\hline if CARs & $15.54 * * *$ & $11.83 * * *$ & $23.52 * * *$ & $23.24 * * *$ & $5.28 * *$ & $24.67 *$ \\
\hline
\end{tabular}

$* * *$ p-value $<.01, * *$ p-value $<.05, *$ p-value $<.1$ 
Table 4e: March 23 ${ }^{\text {rd }}$ event with market model (KP Test)

\begin{tabular}{lcccccc}
\hline Kolari and Pynnonen $(2010)(\mathrm{KP})$ & Test \\
\hline Firm & CAR $(0 ; 5)$ & CAR $(-5 ; 0)$ & CAR $(-5 ; 5)$ & CAR $(0 ; 10)$ & CAR $(-10 ; 0)$ & CAR $(-10 ; 10)$ \\
\hline SYY & $14.08 * * *$ & $-6.86 *$ & 1.62 & $10.82 *$ & $-32.9 * * *$ & $-27.68 * * *$ \\
ALCO & $-10.16 * * *$ & $7.83 * *$ & 1.71. & $-9.57 * *$ & $11.09 * *$ & 5.56 \\
SAFM & $-17.32 * * *$ & $26.8 * * *$ & 4.56 & $-24.51 * * *$ & $28.32 * * *$ & -1.11 \\
KHC & -0.87. & 4.87 & 8.04. & 0.61. & 7.53. & 12.19. \\
CALM & -7.27. & $28.27 * * *$ & $20.68 * * *$ & $-12.01 *$ & $32.94 * * *$ & $20.61 * *$ \\
MDLZ & 4.1. & -0.23 & 4.17 & 4.44. & 0.07 & 4.8. \\
CAG & -5.03. & $23.04 * * *$ & $16.15 * * *$ & 3.88. & $19.17 * * *$ & $21.2 * *$ \\
MMMB & -1.54. & 8.08. & 9.28. & 16.76. & -10.96. & 8.54 \\
SEB & $-5.84 * *$ & $12.8 * * *$ & 1.11. & $-9.77 * * *$ & $9.71 * * *$ & -5.91. \\
HRL & $-9.46 * * *$ & $18.99 * * *$ & $12.99 * * *$ & -7.15. & $24.6 * * *$ & $20.9 * * *$ \\
PPC & $-7.29 *$ & $10.55 * *$ & 1.2. & $-11.25 * *$ & 7.71. & -5.59. \\
BRI & 19.43. & 20.84 & $43.31 * *$ & 16.73. & 10.82. & 30.58. \\
CHEF & $38.84 * * *$ & $-76.4 * * *$ & $-59.84 * * *$ & $48.5 * * *$ & $-107.74 * * *$ & $-81.52 * * *$ \\
TSN & -3.25. & $28.45 * * *$ & $15.07 * * *$ & $-9.34 *$ & $16.85 * * *$ & -2.61. \\
Ptf CARs & 0.6. & $7.64 * * *$ & $5.72 * *$ & 1.3. & 1.23. & 0. \\
\hline
\end{tabular}

$* * *$ p-value $<.01, * * \mathrm{p}$-value $<.05, *$ p-value $<.1$
Table 4f: March 23 $3^{\text {rd }}$ market model (GRANK Test)

\begin{tabular}{lcccccc}
\hline Kolari and Pynnonen (2011) Generalized Rank Test (GRANK) \\
\hline Firm & CAR $(0 ; 5)$ & CAR $(-5 ; 0)$ & CAR $(-5 ; 5)$ & CAR $(0 ; 10)$ & CAR $(-10 ; 0)$ & CAR $(-10 ; 10)$ \\
\hline SYY & $14.08 * * *$ & -6.86 & 1.62 & $10.82 *$ & $-32.9 * * *$ & $-27.68 * * *$ \\
ALCO & $-10.2 * * *$ & $7.83 * *$ & 1.71. & $-9.57 *$ & $11.09 * *$ & 5.56 \\
SAFM & $-17.3 * * *$ & $26.8 * * *$ & 4.56 & $-24.51 * * *$ & $28.32 * * *$ & -1.11 \\
KHC & -0.87. & 4.87 & 8.04 & 0.61. & 7.53. & 12.19 \\
CALM & -7.27. & $28.27 * * *$ & $20.68 * * *$ & $-12.01 *$ & $32.94 * * *$ & $20.61 * *$ \\
MDLZ & 4.1. & -0.23 & 4.17 & 4.44. & 0.07 & 4.8 \\
CAG & -5.03. & $23.04 * * *$ & $16.15 * * *$ & 3.88. & $19.17 * * *$ & $21.2 * *$ \\
MMMB & -1.54. & 8.08. & 9.28. & 16.76. & -10.96. & 8.54 \\
SEB & $-5.84 * *$ & $12.8 * * *$ & 1.11. & $-9.77 * *$ & $9.71 * *$ & -5.91. \\
HRL & $-9.46 * * *$ & $18.99 * * *$ & $12.99 * * *$ & -7.15. & $24.6 * * *$ & $20.9 * * *$ \\
PPC & $-7.29 *$ & $10.55 * *$ & 1.2. & $-11.25 *$ & 7.71. & -5.59. \\
BRID & 19.43. & 20.84 & $43.31 * *$ & 16.73. & 10.82. & 30.58. \\
CHEF & $38.84 * * *$ & $-76.4 * * *$ & $-59.84 * * *$ & $48.5 * * *$ & $-107.74 * * *$ & $-81.52 * * *$ \\
TSN & -3.25. & $28.45 * * *$ & $15.07 * * *$ & $*$ & $16.85 * * *$ & -2.61. \\
Ptf CARs & 2.4. & $11.73 * * *$ & $11.35 * * *$ & 3.54. & $5.9 * *$ & $6.67 *$ \\
\hline
\end{tabular}

$* * * \mathrm{p}$-value $<.01, * * \mathrm{p}$-value $<.05, * \mathrm{p}$-value $<.1$ 
Table 5a: First case of the Covid-19 outbreak event with Google Trends term (“Coronavirus") (KP Test)

\begin{tabular}{|c|c|c|c|c|c|c|c|c|c|c|c|c|c|c|c|c|c|c|c|c|c|}
\hline \multicolumn{22}{|c|}{ Kolari and Pynnonen (2010) (KP) TEST } \\
\hline Events & \multicolumn{6}{|c|}{ 23-Mar } & \multicolumn{2}{|c|}{ 28-Mar } & \multicolumn{2}{|r|}{ 6-Apr } & \multicolumn{3}{|c|}{ 14-May } & \multicolumn{4}{|c|}{ 17-Apr } & \multicolumn{2}{|c|}{ 28-Apr } & \multicolumn{2}{|c|}{ 27-Apr } \\
\hline Windows & CHEF & SAFM & ALCO & BRID & MMMB & PtfCARs & $\mathrm{KHC}$ & PtfCARs & TSN & PtfCARs & SYY & CALM & PtfCARs & MDLZ & HRL & CAG & PtfCARs & SEB & PtfCARs & PPC & Ptf CARs \\
\hline$(0,5)$ & $45.02 * * *$ & $*-6.96$. & -2.23 & 9.91 . & 8.19 & $7.3 * * *$ & $7.93 * *$ & 1.71 . & 5.6 . & $3.07 *$ & 10.23 . & -0.21 & -1.15 . & -5.91 & $-10.4 *$ & 3.03 & 1.67 . & 0.58 & -1.54 . & 4.66 & 2.09 \\
\hline$(-5,0)$ & $-84.7^{* * *}$ & * $22.88 * * *$ & -2.3. & $54.14 * * *$ & * -14.41 & 2.63 . & 3.51 . & $7.12 * * *$ & -4.42 . & 2.49 . & -3.63 . & -0.83 & 1.59 . & -1.13 & 2.55 & 6.44 & 1.82 . & 7.58. & 4.7. & 8.52 & 3.63 \\
\hline$(-5,5)$ & $-60.7^{* * *}$ & * 11.56 * & 1.08. & $61.88 * * *$ & * $\quad 0.03$. & $8.15^{* * *}$ & $11.43 * *$ & $8.83 * * *$ & 1.27. & $4.6 * *$ & 4.73. & -1.53. & 2.27 . & -4.7 . & -6.84 & 9.89 . & 3.57 . & 1.09 & 1.38. & 10.01 . & 3.12 \\
\hline$(0,10)$ & $55.92 * * *$ & * -9.75 & -0.42 . & 10.93 & $25.56 *$ & $10.12 * * *$ & $12.35 * *$ & $5.44 * *$ & $12.19 * *$ & $4.36 *$ & 14.64 . & -0.22 . & -0.41 . & -7.34 . & $-12.25 *$ & 1.79 . & 6.04 . & 5.69 & 3.15 . & 11.9 & 4.89 \\
\hline$(-10,0)$ & $-118 * * *$ & * 23.94 *** & -4.04. & $58.94 * * *$ & * $\quad-43.6 * * *$ & $\quad-5.55 * *$ & $9.96 *$ & $8.55 * * *$ & -0.75 & $9.26 * * *$ & -7.92 . & 0.28 . & -2.31 & -4.9 . & -2.16 & 8.68 . & 0.88 . & 0.66 & 4.6 . & 9.1 . & 2.59 \\
\hline$(-10,10)$ & $-83.5 * * *$ & * 9.82 . & 1.14 . & $67.71 * *$ & -11.8 & 2.79 & $22.31 * * *$ & $* \quad 13.99 * * *$ & $11.53 *$ & $12.66 * * *$ & 4.84. & -0.43 & -0.89 . & -9.9 . & -13.4 & 10.9 . & 7. & -0.73 & 5.97. & 17.82 . & 4.89 \\
\hline
\end{tabular}

$* * *$ p-value $<.01, * *$ p-value $<.05, *$ p-value $<.1$

Table 5b: First case of the Covid-19 outbreak event with Google Trends term ("Meat processor") and financial beta (KP Test)

\begin{tabular}{|c|c|c|c|c|c|c|c|c|c|c|c|c|c|c|c|c|c|c|c|c|c|}
\hline \multicolumn{22}{|c|}{ Kolari and Pynnonen (2010) (KP) Test with Google Trends and Beta for 1 st cases of Covid-19 in Individual firms } \\
\hline Events & \multicolumn{6}{|c|}{ 23-Mar } & \multicolumn{2}{|c|}{ 28-Mar } & \multicolumn{2}{|c|}{ 6-Apr 1} & \multicolumn{3}{|c|}{\begin{tabular}{|c|c|c|} 
14-May & \\
\end{tabular}} & \multicolumn{4}{|c|}{$17-\mathrm{Apr}$} & \multicolumn{2}{|c|}{ 28-Apr } & \multicolumn{2}{|c|}{$27-\mathrm{Apr}$} \\
\hline 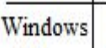 & CHEF & SAFM & $\mathrm{ALCO}$ & BRD & MMMB & PtfCARs & $\mathrm{KHC}$ & PtfCARs & TSN & PtfCARs & SYY & CALM & PtfCARs & MDLZ & HRL & $\mathrm{CAG}$ & PtfCARs & SEB & PtfCARs & PPC & Ptf CARs \\
\hline$(0,5)$ & $53.53 * * *$ & $-16.5 * * *$ & 0.14 & $116.7^{* * *}$ & 14.86 & $15.54 * * *$ & 2.62 . & $5.7^{* * *}$ & $17.1 * * *$ & 0.14 . & 3.73 . & 3.19 . & -0.13 . & $54.22 * * *$ & $20.82 * * *$ & $-40.6 * * *$ & $18.79 * * *$ & 0.66 . & 0.97 . & $16.96^{* * *}$ & * 3.98 . \\
\hline$(-5,0)$ & $-67.2 * * *$ & $15.22 * * *$ & -3.55 . & $112.2 * * *$ & 2.42 . & $11.83 * * *$ & -1.07 & $14.08 * * *$ & $7.58 * *$ & -0.04 & -7.98 . & 0.52 . & 2.1 . & $58.87 * * *$ & $33.75^{* * *}$ & $-38.6 * * *$ & $18.14 * * *$ & $7.94 *$ & $7.02 * *$ & $17.71 * * *$ & * 3.59 . \\
\hline$(-5,5)$ & $-37.5^{* * *}$ & -5.39 . & 2.41 & $209.8 * * *$ & 20.96 . & $23.52 * * *$ & 1.55 . & $19.78 * * *$ & $22.85 * * *$ & -0.15 & -4.99 . & 2.55 & 3.64 . & $105.18 * * *$ & $50.46 * * *$ & $-70.9 * * *$ & $34.04 * * *$ & 1.52 . & 5.57 . & $28.61 * * *$ & * 4.31 . \\
\hline$(0,10)$ & $73.96 * * *$ & $-27.7 * * *$ & 3.02 . & $190.5 * * *$ & $40.68 * * *$ & $23.24 * * *$ & -0.15 & $14.11 * * *$ & $32.7 * * *$ & -0.6 & 2.77 & 5.97. & 1.51. & $102.39 * * *$ & $44.89 * * *$ & $-75 * * *$ & $39.6 * * *$ & 5.93 . & $7.98 *$ & $32.91 * * *$ & * 7.02 . \\
\hline$(-10,0)$ & $-94.4 * * *$ & $12.45^{*}$ & -5.72 . & $134 * * *$ & -20.46 . & $5.28 * *$ & 0.23 & $21.64 * * *$ & $23.75 * * *$ & $6.74 * * *$ & $-20.53 *$ & 5.44 & 0.41 . & $108.48 * * *$ & $56.03 * * *$ & $-74.2 * * *$ & $30.61 * * *$ & 1.09 . & $7.71 *$ & $25.48 * * *$ & * 1.35 . \\
\hline$(-10,10)$ & $-44.2 * * *$ & $-19.3 * *$ & 3.12 . & $305.3 * * *$ & 23.9 . & $24.67 * * *$ & 0.08 . & $35.75 * * * *$ & $54.61 * * *$ & $5.89 *$ & -18.5. & 10.25 . & 3.59 . & $202.96 * * *$ & $96.8 * * *$ & $-141 * * *$ & $67.32 * * *$ & -0.06 . & $13.22 * *$ & $52.34 * * *$ & * 5.11 . \\
\hline
\end{tabular}

$* * *$ p-value $<.01, * *$ p-value $<.05, *$ p-value $<.1$

Table 5c: First case of the Covid-19 outbreak market model (KP Test)

\begin{tabular}{|c|c|c|c|c|c|c|c|c|c|c|c|c|c|c|c|c|c|c|c|c|c|}
\hline \multicolumn{22}{|c|}{ Kolari and Pynnonen (2010) (KP) TEST } \\
\hline \multirow{2}{*}{$\frac{\text { Events }}{\text { Windows }}$} & \multicolumn{6}{|c|}{ 23-Mar } & \multicolumn{2}{|c|}{ 28-Mar } & \multicolumn{2}{|r|}{ 6-Apr } & \multicolumn{3}{|c|}{ 14-May } & \multicolumn{4}{|c|}{ 17-Apr } & \multicolumn{2}{|c|}{ 28-Apr } & \multicolumn{2}{|c|}{ 27-Apr } \\
\hline & CHEF & SAFM & ALCO & BRID & MMMB & Ptf CARs & $\mathrm{KHC}$ & Ptf CARs & TSN $\mathrm{F}$ & PtfCARs & SYY & CALM & PtfCARs & MDLZ & HRL & $\mathrm{CAG}$ & PtfCARs & SEB & PffCARs & PPC & Ptf CARs \\
\hline$(0,5)$ & 38.84 *** & * $-17.3 * * *$ & ${ }^{*}-10.2 * * *$ & * 19.43. & -1.54. & 0.6 . & $6.45 *$ & 0.69 & -0.23. & -3.05 & 7.23. & -2.1 & -2.8 . & -5.17 & -8.76 & 0.78 & -0.52 . & -1.69 & -2.85 & 2.37 & 0.84 \\
\hline$(-5,0)$ & $-76.4 * * *$ & * $\quad 26.8 * * *$ & $\quad 7.83 * *$ & 20.84 & 8.08. & $7.64 * * *$ & -1.34. & 2.13 . & $-8.43 * *$ & -0.83 & -7.95 . & -0.23 & 0.44 . & -1.21 & 2.49 & 2.58 & -0.86 & 4.35 & 3.22 . & 5.37 & 2.44 \\
\hline$(-5,5)$ & $-59.8 * * *$ & * 4.56 & 1.71 & $43.31 * *$ & 9.28 . & $5.72 * *$ & 5.11. & 2.82. & -6.63 & -2.36 & -2.3 & -2.25 & -0.22 . & -3.84 & -4.22 & 5.67 & -0.68 . & -4.33 & -1.24 & 4.82 & 1.03 \\
\hline$(0,10)$ & $48.5^{* * *}$ & $*-24.5 * * *$ & * $-9.57 * *$ & 16.73 & 16.76 . & 1.3. & 5.85. & -0.78 & 4.51. & -1.99 & 9.01. & -3.4 & -3.38 . & -6.33 & -8.55 & -1.04 & 1.96. & 1.33 & 0.71 & 7.13 & 2.38 \\
\hline$(-10,0)$ & $-108 * * *$ & * $28.32 * * *$ & * $11.09 * *$ & 10.82 & -10.96 & 1.23. & 7.58. & $7.25 * * *$ & $-9.34 *$ & 1.3 & -17. & 3.3 & -4.06 . & -5.74 & -6.05 & -3.06 & -4.7 . & -6.25 & 1.85. & 3.53 & 0.13 \\
\hline$(-10,10)$ & $-81.5 * * *$ & * -1.11 . & 5.56 & 30.58 & 8.54 . & 0 . & $13.43 *$ & $6.47 *$ & -2.79 & 0.82 & -9.54. & -0.02 & -5.3 . & -9.52 . & -12.56 & -1.79 & -2.02 . & -11.91 & 0.95 . & 7.73 & 0.26 \\
\hline
\end{tabular}

$* * * \mathrm{p}$-value $<.01, * * \mathrm{p}$-value $<.05, * \mathrm{p}$-value $<.1$ 
Table 5d: First case of the Covid-19 outbreak event with Google Trends term (“Coronavirus") (GRANK Test)

\begin{tabular}{|c|c|c|c|c|c|c|c|c|c|c|c|c|c|c|c|c|c|c|c|c|c|}
\hline \multicolumn{22}{|c|}{ Kolari and Pynnonen (2011) Generalised Rank Test (GRANK) } \\
\hline \multirow{2}{*}{$\frac{\text { Events }}{\text { Windows }}$} & \multicolumn{6}{|c|}{ 23-Mar } & \multicolumn{2}{|c|}{ 28-Mar } & \multicolumn{2}{|r|}{ 6-Apr } & \multicolumn{3}{|c|}{ 14-May } & \multicolumn{4}{|c|}{ 17-Apr } & \multicolumn{2}{|c|}{ 28-Apr } & \multicolumn{2}{|c|}{ 27-Apr } \\
\hline & CHEF & SAFM & ALCO & $\mathrm{BRID}$ & MMMB & Ptf CARs & $\mathrm{KHC}$ & PtfCARs & TSN & PtfCARs & SYY & CALM & PtfCARs & MDLZ & HRL & $\mathrm{CAG}$ & Ptf CARs & SEB & Ptf CARs & PPC & PtfCARs \\
\hline$(0,5)$ & $45.02 * * *$ & $*-6.96$. & -2.23 . & 9.91 . & 8.19 . & $8.9 * * *$ & $7.93 * *$ & 2.11. & 5.6. & $3.35 *$ & 10.23 . & -0.21 & -1.63. & -5.91 . & $-10.4 *$ & 3.03 . & 1.45 . & 0.58 & -1.95 . & 4.66 . & 1.67 \\
\hline$(-5,0)$ & $-84.7 * * *$ & $* 22.88 * * *$ & * -2.3. & $54.14 * * *$ & - -14.41 & $6.63 * * *$ & 3.51 & 8.55 *** & -4.42. & $3.03 *$ & -3.63 . & -0.83 & 1.13 . & -1.13 . & 2.55 & 6.44 & 1.58. & 7.58 & 4.19 . & 8.52 . & 3.16 \\
\hline$(-5,5)$ & $-60.7 * * *$ & $* 11.56 *$ & 1.08. & $61.88 * * *$ & $\quad 0.03$. & $13.52 * * *$ & $11.43^{* *}$ & $10.66 * * *$ & 1.27. & $5.27 * *$ & 4.73. & -1.53 & 1.39 . & -4.7 . & -6.84 & 9.89 . & 3.08 . & 1.09 & 0.57 . & 10.01. & 2.33 \\
\hline$(0,10)$ & $55.92 * * *$ & $* \quad-9.75$ & -0.42 . & 10.93 . & $25.56 *$ & $12.03 * * *$ & $12.35^{* *}$ & $6.04 * *$ & $12.19 * *$ & $4.63^{* *}$ & 14.64 . & -0.22 & -1.31 . & -7.34 & $-12.25 *$ & 1.79. & 5.65. & 5.69 & 2.28 . & 11.9. & 4.1. \\
\hline$(-10,0)$ & $-118 * * *$ & $* 23.94 * * *$ & * -4.04. & $58.94 * * *$ & * $\quad-43.6 * * *$ & -1.08 & $9.96 *$ & 13.71 **** & -0.75 . & $11.27^{* * *}$ & -7.92 . & 0.28 & -3.24 . & -4.9 . & -2.16 & 8.68 & 0.85 . & 0.66 & 3.7 . & 9.1 . & 1.71 \\
\hline$(-10,10)$ & $-83.5 * * *$ & * $\quad 9.82$. & 1.14. & $67.71 * *$ & -11.8 . & $8.95 * * *$ & 22.31 *** & $\Rightarrow \quad 19.75 * * *$ & $11.53 *$ & $14.8 * * *$ & 4.84. & -0.43 & -2.66 . & -9.9 . & -13.4 . & 10.9 . & 6.55 . & -0.73. & 4.3. & 17.82. & 3.31 \\
\hline
\end{tabular}

$* * *$ p-value $<.01, * *$ p-value $<.05, *$ p-value $<.1$

Table 5e: First case of the Covid-19 outbreak event with Google Trends term ("Meat processor") and financial beta (GRANK Test)

\begin{tabular}{|c|c|c|c|c|c|c|c|c|c|c|c|c|c|c|c|c|c|c|c|c|c|}
\hline \multirow{3}{*}{$\frac{\text { Events }}{\text { Windows }}$} & \multicolumn{21}{|c|}{ Kolari and Pynnonen (2011) Generalised Rank Test (GRANK) with Google Trends and Beta for 1st cases of Covid-19 in Individual firms } \\
\hline & \multicolumn{6}{|c|}{ 23-Mar } & \multicolumn{2}{|c|}{ 28-Mar } & \multicolumn{2}{|c|}{ 6-Apr } & \multicolumn{3}{|c|}{ 14-May } & \multicolumn{4}{|c|}{ 17-Apr } & \multicolumn{2}{|c|}{ 28-Apr } & \multicolumn{2}{|c|}{ 27-Apr } \\
\hline & CHEF & SAFM & ALCO & BRID & MMMB & Ptf CARs & KHC & Ptf CARs & TSN & Ptf CARs & SYY & CALM & Ptf CARs & MDLZ & HRL & CAG & Ptf CARs & SEB & Ptf CARs & PPC & Ptf CARs \\
\hline$(0,5)$ & $53.53 * * *$ & $-16.5 * * *$ & 0.14 . & $116.7^{* * *}$ & 14.86 . & $15.54 * * *$ & 2.62. & $5.7 * * *$ & $17.1 * * *$ & 0.14 . & 3.73 . & 3.19 . & -0.13. & $54.22 * * *$ & $20.82 * * *$ & $-40.6 * * *$ & $18.79 * * *$ & 0.66 . & 0.97 . & $16.96 * * *$ & * 3.98 . \\
\hline$(-5,0)$ & $-67.2 * * *$ & $15.22 * * *$ & -3.55 & $112.2 * * *$ & 2.42 . & $11.83^{* * *}$ & -1.07. & $14.08 * * *$ & $7.58 * *$ & -0.04 & -7.98. & 0.52 . & 2.1 . & $58.87 * * *$ & $33.75 * * *$ & $-38.6 * * *$ & $18.14 * * *$ & $7.94 *$ & $7.02 * *$ & $17.71 * * *$ & * 3.59 . \\
\hline$(-5,5)$ & $-37.5 * * *$ & -5.39 & 2.41 & $209.8^{* * *}$ & 20.96 . & $23.52 * * *$ & 1.55. & $19.78 * * *$ & $22.85 * * *$ & -0.15 . & -4.99 . & 2.55 & 3.64 . & $105.18 * * *$ & $50.46 * * *$ & $-70.9 * * *$ & $34.04 * * *$ & 1.52. & 5.57 & $28.61 * * *$ & * 4.31 . \\
\hline$(0,10)$ & $73.96 * * *$ & $-27.7^{* * *}$ & 3.02 & $190.5 * * *$ & $40.68 * * *$ & $23.24 * * *$ & -0.15. & $14.11 * * *$ & $32.7^{* * *}$ & -0.6 . & 2.77 . & 5.97 . & 1.51 & $102.39 * * *$ & $44.89 * * *$ & $-75 * * *$ & $39.6 * * *$ & 5.93. & $7.93 *$ & $32.91 * * *$ & * 7.02 . \\
\hline$(-10,0)$ & $-94.4 * * *$ & $12.45 *$ & -5.72 . & $134 * * *$ & -20.46 & $5.28 * *$ & 0.23 . & $21.64 * * *$ & $23.75 * * *$ & $6.74 * * *$ & $-20.53 *$ & 5.44 . & 0.41 . & $108.48 * * *$ & $56.03 * * *$ & $-74.2 * * *$ & $30.61 * * *$ & 1.09 & $7.71 *$ & $25.48 * * *$ & * 1.35 . \\
\hline$(-10,10)$ & $-44.2 * * *$ & $-19.3 * *$ & 3.12 & $305.3 * * *$ & 23.9 & $24.67 * * *$ & 0.08 & $35.75 * * *$ & $54.61 * * *$ & $5.89 *$ & -18.5 & 10.25 & 3.59 & $202.96 * * *$ & $96.8 * * *$ & $-141 * * *$ & $67.32 * * *$ & -0.06 & $13.22 * *$ & $52.34 * * *$ & * 5.11 \\
\hline
\end{tabular}

$* * *$ p-value $<.01, * *$ p-value $<.05, *$ p-value $<.1$

Table 5f: First case of the Covid-19 outbreak market model (GRANK Test)

\begin{tabular}{|c|c|c|c|c|c|c|c|c|c|c|c|c|c|c|c|c|c|c|c|c|c|}
\hline \multicolumn{22}{|c|}{ Kolari and Pynnonen (2011) Generalised Rank Test (GRANK) } \\
\hline \multirow{2}{*}{$\frac{\text { Events }}{\text { Windows }}$} & \multicolumn{6}{|c|}{ 23-Mar } & \multicolumn{2}{|r|}{ 28-Mar } & \multicolumn{2}{|c|}{ 6-Apr } & \multicolumn{3}{|c|}{ 14-May } & \multicolumn{4}{|c|}{ 17-Apr } & \multicolumn{2}{|c|}{ 28-Apr } & \multicolumn{2}{|c|}{ 27-Apr } \\
\hline & CHEF & SAFM & ALCO & BRD & MMMB & PtfCARs & $\mathrm{KHC}$ & PffCARs & TSN P & PffCARs & SYY & CALM & PtfCARs & MDLZ & HRL & $\mathrm{CAG}$ & PtfCARs & SEB & PtfCARs & PPC & Ptf CARs \\
\hline$(0,5)$ & $38.84 * * *$ & * $-17.3^{* * *}$ & $-10.2 * * *$ & 19.43 & -1.54 . & 2.4 . & 6.45 . & 1.21. & -0.23 & -2.66 . & 7.23 & -2.1 & -2.6 . & -5.17 . & -8.76 . & 0.78 & -0.25 . & -1.69 . & -2.45 & 2.37 & 1.23 \\
\hline$(-5,0)$ & $-76.4 * * *$ & * $26.8 * * *$ & $7.83 * *$ & 20.84 & 8.08. & $11.73^{* * *}$ & -1.34 & $3.7 *$ & $-8.43 * *$ & -0.16 . & -7.95 . & -0.23. & 0.71 . & -1.21. & 2.49 . & 2.58 . & -0.63 . & 4.35 . & 3.5 . & 5.37 & 2.7 \\
\hline$(-5,5)$ & $-59.8 * * *$ & 4.56 & 1.71. & $43.31 *$ & 9.28 . & $11.35^{* * *}$ & 5.11. & $4.91 *$ & -6.63 & -1.45 . & -2.3 & -2.25 . & 0.21 . & -3.84 . & -4.22. & 5.67 & -0.22. & -4.33. & -0.6 . & 4.82 & 1.65 \\
\hline$(0,10)$ & $48.5^{* * *}$ & * $-24.5 * * *$ & $-9.57 *$ & 16.73 & 16.76 . & 3.54 & 5.85. & 0.08 & 4.51 & -1.46 . & 9.01 & -3.4 . & -3.04 . & -6.33. & -8.55 . & -1.04 & 2.6 . & 1.33. & 1.31 . & 7.13 & 2.99 \\
\hline$(-10,0)$ & $-108 * * *$ & * $28.32 * * *$ & $11.09 * *$ & 10.82 & -10.96 . & $5.9 * *$ & 7.58. & $12.65^{* * * *}$ & $-9.34 *$ & 3.54 . & -17. & 3.3. & -3.6 . & -5.74 . & -6.05 . & -3.06 & -4.1 . & -6.25 . & 2.3. & 3.53 & 0.59 \\
\hline$(-10,10)$ & $-81.5 * * *$ & * -1.11 & 5.56 . & 30.58 . & 8.54. & $6.67 *$ & $13.43 *$ & $12.73^{* * *}$ & -2.79 & 3.45 . & -9.54 . & -0.02. & -4.54. & -9.52 . & -12.56 & -1.79 . & -0.84 . & -11.91. & 1.97. & 7.73. & 1.29 \\
\hline
\end{tabular}

$* * *$ p-value $<.01, * *$ p-value $<.05, *$ p-value $<.1$ 
Table 6a: The Lockdown event with Google Trends term (“Coronavirus”) (KP Test)

\begin{tabular}{|c|c|c|c|c|c|c|c|c|c|c|c|c|c|c|c|c|c|c|c|c|c|c|c|}
\hline \multicolumn{24}{|c|}{ Kolari and Pynnonen (2010) (KP) Test with Google Trends } \\
\hline \multirow{2}{*}{$\begin{array}{l}\text { Events } \\
\text { Windows }\end{array}$} & \multicolumn{2}{|r|}{ 19-Mar } & \multicolumn{4}{|c|}{ 21-Mar } & \multicolumn{3}{|c|}{ 23-Mar } & \multicolumn{2}{|c|}{ 26-Mar } & \multicolumn{2}{|c|}{ 27-Mar } & \multicolumn{2}{|c|}{ 30-Mar } & \multicolumn{3}{|c|}{ 1-Apr } & \multicolumn{3}{|c|}{ 2-Apr } & \multicolumn{2}{|r|}{ 3-Apr } \\
\hline & BRID & PtfCARs & MDLZ & CAG & MMMB & Ptf CARs & TSN & CHEF $\quad \mathrm{I}$ & Ptf CARs & PPC & PtfCARs & HRL & PtfCARs & SEB & PtfCARs & SAFM & $\mathrm{KHC}$ & Ptf CARs & SYY & $\mathrm{ALCO}$ & Ptf CARs & CALM & Ptf CARs \\
\hline$(0,5)$ & 23.5 . & $13.49 * * *$ & 0.26 & -2.84 & 2.75 & 2.13 . & -3.25 & $38.84 * *$ & 0.6 & -4.79 . & -1.88 & $13.1 * * *$ & * -0.65 . & -6.56 & -0.83 & $-9.36 *$ & 3.71 & -3.28 & 5.84 . & -5.41 & -2.39 . & -6.85 . & -0.43 \\
\hline$(-5,0)$ & 13.42. & -2.96 & 0.07 & 21.19 *** & 10.82 & $5.12 * * *$ & 28.45 *** & $-76.4 * * *$ & $7.64 * * *$ & 3.5 & $13.49 * * *$ & $-10.2 * * *$ & * $\quad 5.56 * * *$ & -5.84 & 0.6 . & $-17.9 * * *$ & 2.01 & -0.06 . & $-11 * * *$ & * -10.1 *** & * $\quad-1.88$. & 6.19 . & -0.65 \\
\hline$(-5,5)$ & 28.55 & 3.94. & 0.33 . & $18.35 * * *$ & 13.57 & $7.25 * * *$ & $15.07 * * *$ & $-59.84 * * *$ & $5.72 * *$ & 2.8 . & $2.8 * * *$ & -0.82 & $6.25 * *$ & $-9.77 *$ & 1.3. & $-25.1 * * *$ & 5.59 & -3.89 . & -2.6 & $-19 * * *$ & -2.2 . & -4.72 . & -2.12 \\
\hline$(0,10)$ & 23.7. & $11.8 * * *$ & * $8.83 * *$ & $10.39 *$ & 18.56. & 2.82 . & $-9.34 *$ & $48.5 * * *$ & 1.3 & -6.56 . & -2.2 & 0.5 . & -2.12 & -2.96 . & -2.36 . & -5 & 8.69 & -3.43 . & 4.3. & $-11.6 * *$ & -4.7 . & -7.42 . & -1.8. \\
\hline$(-10,0)$ & 20.38. & -2.95 . & 0.37 . & 17.32 *** & -8.22 & -1.3 . & $16.85 * * *$ & $-107.7 * * *$ & 1.23 & 5.01 . & 3.94. & $9.07 *$ & 4.18 . & 1.11. & $5.72 * *$ & -0.13. & 1.7. & 7.86 **** & * 23.72 *** & * $13.3^{* *}$ & $11.8 * * *$ & 3.84. & $6.25 * *$ \\
\hline$(-10,10)$ & 35.7. & 2.26 . & 9.19. & 27.71 *** & 10.34 & 1.52. & -2.61. & $-81.52 * * *$ & 0. & 2.54 . & 1.93. & 5.89 & 3.4 . & 0.78. & 4.89. & -2.98 . & 10.26 & 3.88. & $30.6^{* * *}$ & -1.75 & $9.77 * *$ & -7.64. & 3.41. \\
\hline
\end{tabular}

$* * *$ p-value $<.01, * *$ p-value $<.05, *$ p-value $<.1$

Table 6b: The Lockdown event with Google Trends term ("Meat processor") and financial beta (KP Test)

\begin{tabular}{|c|c|c|c|c|c|c|c|c|c|c|c|c|c|c|c|c|c|c|c|c|c|}
\hline \multicolumn{22}{|c|}{ Kolari and Pynnonen (2011) with Google Trends and Beta for Lockdown in various states } \\
\hline Events & \multicolumn{2}{|c|}{ 19-Mar } & \multicolumn{3}{|c|}{ 21-Mar } & \multicolumn{3}{|c|}{ 23-Mar } & \multicolumn{2}{|c|}{ 26-Mar } & \multicolumn{2}{|c|}{ 27-Mar } & \multicolumn{2}{|c|}{ 30-Mar } & \multicolumn{3}{|c|}{ 1-Apr } & \multicolumn{3}{|c|}{ 2-Apr } & 3-Apr \\
\hline Windows & BRID & PtfCARs & MDLZ CAG & MMMB & Ptf CARs & TSN & CHEF & Ptf CARs & PPC & Ptf CARs & HRL & Ptf CARs & SEB & Ptf CARs & SAFM & KHC & Ptf CARs & SYY & ALCO & Ptf CARs & CALM PtfCARs \\
\hline$(0,5)$ & $156.1 * * *$ & $26.81 * * *$ & * $-22 * * *-7.64 *$ & 15.52 & $14.68 * * *$ & 1.04. & $53.53 * * *$ & * 15.54 **** & 2.6 . & $10.5 * * *$ & * 12.52 *** & $7.93 * * *$ & $13.48 * * *$ & * 7.71 *** & $-8.3 *$ & -1.91 & 2.23 & $29.63 * * *$ & 2.8 . & 1.77 . & $-22.5 * * *-3.61 * *$ \\
\hline$(-5,0)$ & $141.6 * * *$ & -0.69 & $-25.6 * * * 4.22$ & 6.1 . & $7.99 * * *$ & 24.17 *** & $*-67.19 * * *$ & * $11.83 * * *$ & $13.27 * * *$ & $31.25 * * *$ & -5.04 & $21.78 * * *$ & $19.44 * * *$ & * $14.73 * * *$ & $-18.3 * * *$ & -3.64 & $4.51 * * *$ & $9.73 * *$ & $-9 * * *$ & * -0.49 . & $-13.7^{* * *}-7.88 * *$ \\
\hline$(-5,5)$ & $269.4 * * *$ & $18.27 * * *$ & * $-47.6 * * * 3.42$ & 21.62 & $22.66 * * *$ & 14.52 ** & $-37.46 * * *$ & * 23.52 **** & $17.66 * * *$ & $36.76 * * *$ & * 5.31 . & $30.77 * * *$ & $31.05 * *$ & * $21.8 * * *$ & $-22.1 * * *$ & $* 3.61$ & $6.97 * * *$ & $37.83 * * *$ & $-11 * *$ & 2.49 . & $-36.7^{* * *}-11.1 * * *$ \\
\hline$(0,10)$ & $274.8 * * *$ & $28.29 * * *$ & $*-37.9 * * *-5.92$ & 36.52 ** & $20.99 * * *$ & -5.01 . & $73.96 * * *$ & * $23.24 * * *$ & 7.05 & $25.12 * * *$ & $8.3 *$ & $21.94 * * *$ & $39.74 * * *$ & * $15.27 * * *$ & -5.97 & -4.1 & $5.39 * *$ & $45.22 * * *$ & 0.45 & 0.34 . & $-37.8^{* * *}-8.93 * *$ \\
\hline$(-10,0)$ & $197.5^{* * *}$ & $-5.44 * *$ & $-38.2 * * *-7.91$ & -16.78. & 1.43. & 10.59 ** & $-94.36 * * *$ & * $5.28 * *$ & $19.62 * * *$ & $26.12 * * *$ & * $14.45 * * *$ & $30.62 * * *$ & $31.37 * *$ & * $22.29 * * *$ & -2.61 & $-9.39 *$ & $17.4 * * *$ & $62.24 * * *$ & $16.33 * * *$ & * $16.37 * * *$ & $-25.3 * * * \quad-0.47$ \\
\hline$(-10,10)$ & $444 * * *$ & $15 * * *$ & * $\quad-76 * * *-13.8 *$ & 19.74. & $22.42 * * *$ & -5.1 & $-44.21 * * *$ & * $24.67 * * *$ & $28.47 * * *$ & $46.25 * * *$ & * $20.58 * * *$ & $53.62 * * *$ & $69.25 * * *$ & * $36.91 * * *$ & -4.05 & -11.6 & $23.1 * * *$ & $105.9 * * *$ & 12.02 * & $17.91 * * *$ & * $-63.6 * * *-9.04 * * *$ \\
\hline
\end{tabular}

$* * *$ p-value $<.01, * *$ p-value $<.05, *$ p-value $<.1$

Table 6c: The Lockdown event with market model (KP Test)

\begin{tabular}{|c|c|c|c|c|c|c|c|c|c|c|c|c|c|c|c|c|c|c|c|c|c|c|c|}
\hline \multicolumn{24}{|c|}{ Kolari and Pynnonen (2010) (KP) Test } \\
\hline Events & \multicolumn{2}{|c|}{ 19-Mar } & \multicolumn{4}{|c|}{ 21-Mar } & \multicolumn{3}{|c|}{ 23-Mar } & \multicolumn{2}{|c|}{ 26-Mar } & \multicolumn{2}{|c|}{ 27-Mar } & \multicolumn{2}{|c|}{ 30-Mar } & \multicolumn{3}{|c|}{ 1-Apr } & \multicolumn{3}{|c|}{ 2-Apr } & \multicolumn{2}{|r|}{ 3-Apr } \\
\hline Windows & BRID & Ptf CARs & MDLZ & CAG & MMMB & Ptf CARs & TSN & CHEF & Ptf CARs & PPC & \begin{tabular}{l|l} 
Ptf CARs & I
\end{tabular} & HRL & \begin{tabular}{l|l} 
Ptf CARs & $S$
\end{tabular} & SEB & \begin{tabular}{l|l} 
Ptf CARs & $S$
\end{tabular} & SAFM & $\mathrm{KHC}$ & Ptf CARs & SYY & ALCO & Ptf CARs & CALM & PtfCARs \\
\hline$(0,5)$ & 18.29 . & $19.4 * * *$ & * 1.89 & 3.81 & 9.88 . & $7.3^{* * *}$ & $6.33 *$ & $45.02 * * *$ & $7.3 * * *$ & -0.11 & 1.08 . & $11.29 * * *$ & * -0.66 . & -2.52 & 2.8 . & -1.9 . & $7.5^{*}$ & 0.54 & $11.4^{* * *}$ & 2.31 & $3.28 *$ & -1.57 & $4.22 * *$ \\
\hline$(-5,0)$ & $36.8 * *$ & $-6.63 * * *$ & -4.14 & $15.68 * * *$ & -8.16 & 0.85 . & $19.04 * * *$ & $-84.67 * * *$ & 2.63 & 10.26 ** & $19.4 * * *$ & $-7.24 * *$ & $9.92 * * *$ & 2.59 . & $7.04 * * *$ & $-13 * * *$ & 4.61 & 2.19 . & $-6.79 *$ & $-7.74 *$ & 0.69 . & 4.61 . & -0.6 \\
\hline$(-5,5)$ & 46.21 ** & $5.65 * *$ & -2.25 & $19.5^{* * *}$ & $\quad 1.72$. & $8.15 * * *$ & $16.66 * * *$ & $-60.67 * * *$ & $8.15 * * *$ & 11.87 ** & $17.83 * * *$ & 1.76 & 11.6 **** & 0.77. & $9.92 * * * *$ & $-11.3^{*}$ & $12.67 * *$ & 3.23 . & 6.18 . & $-10.3^{* *}$ & $5.02 * *$ & -0.43. & 2.79 \\
\hline$(0,10)$ & 30.56. & $17.66 * * *$ & * 9.35 ** & ** 18.11 *** & 21.14. & $8.85 * * *$ & 2.92. & $55.92 * * *$ & $10.12 * * *$ & 4.73 & $6.59 * * *$ & 3.77 & 3.9 . & 5.83. & $5.22 * *$ & 7.01 & 14.86 *** & 2.56 & $13.49 * * *$ & * -1.2 & 3.5 . & -0.24 . & $5.05 * *$ \\
\hline$(-10,0)$ & 65.58 *** & $-10.83 * * *$ & $-7.05 *$ & 9.26 . & -37.36 *** & $-7.33 * * *$ & 4.71. & $-118.4 * * *$ & $-5.55 * *$ & 12.36 ** & $6.13 * *$ & $11.36^{* *}$ & $9.2 * * *$ & 1.74. & $8.47 * * *$ & 6.84. & 5.48. & $10.75 * * *$ & $31.66 * * *$ & * $18.4 * * *$ & $16.97 * * *$ & * 7.34. & $10.63 * * *$ \\
\hline$(-10,10)$ & $87.26 * * *$ & -0.28 & 2.31. & $27.37 * * *$ & -16.22 & 1.52. & -1.09. & $-83.52 * * *$ & 2.79 & 18.8 ** & $10.08 * * *$ & $12.83 * *$ & $15.45 * *$ & 8.26. & $13.77 * * *$ & $17.47 * *$ & $20.9 * * *$ & $13.8 * *$ & $46.72 * * *$ & * 12.4 ** & $21.52 * * *$ & * 3.62. & $14.84 * * *$ \\
\hline
\end{tabular}

$* * *$ p-value $<.01, * *$ p-value $<.05, *$ p-value $<.1$ 
Table 6d: The Lockdown event with Google Trends term ("Coronavirus") (GRANK Test)

\begin{tabular}{|c|c|c|c|c|c|c|c|c|c|c|c|c|c|c|c|c|c|c|c|c|c|c|c|}
\hline \multicolumn{24}{|c|}{ Kolari and Pynnonen (2011) Generalised Rank Test (GRANK) with Google Trends } \\
\hline Events & \multicolumn{2}{|r|}{ 19-Mar } & \multicolumn{4}{|c|}{ 21-Mar } & \multicolumn{3}{|c|}{ 23-Mar } & \multicolumn{2}{|c|}{ 26-Mar } & \multicolumn{2}{|c|}{ 27-Mar } & \multicolumn{2}{|c|}{ 30-Mar } & \multicolumn{3}{|c|}{ 1-Apr } & \multicolumn{3}{|c|}{ 2-Apr } & \multicolumn{2}{|c|}{ 3-Apr } \\
\hline Windows & BRD & Ptf CARs & MDLZ & CAG & MMMB & Ptf CARs & TSN & CHEF & PtfCARs & PPC & \begin{tabular}{l|l} 
Ptf CARs & H
\end{tabular} & HRL & Ptf CARs & SEB & Ptf CARs & SAFM & $\mathrm{KHC}$ & PtfCARs & SYY & $\mathrm{ALCO}$ & Ptf CARs & CALM & Ptf CARs \\
\hline$(0,5)$ & 23.5 & $15.63 * * *$ & 0.26 & -2.84 & 2.75 . & $3.7 * *$ & -3.25 . & $38.84 * * *$ & 2.4 . & -4.79. & -0.95 . & 13.1 *** & 0.04 & -6.56 & -0.16 & -9.36 * & 3.71 . & -2.77 & 5.84. & -5.41 . & -1.99 . & -6.85. & -0.04 . \\
\hline$(-5,0)$ & 13.42. & 1.03 & 0.07. & $21.19 * * *$ & 10.82 & $8.95 * * *$ & $28.45 * * *$ & $-76.4 * * *$ & $11.73 * * *$ & 3.5 . & $15.63 * * *$ & $-10.2 * * *$ & $7.32 * * *$ & -5.84 & 2.4 . & $-17.9 * * *$ & 2.01 . & 1.01. & $-11 * * *$ & $*-10.1$ ** & -0.95 . & 6.19 . & 0.04 . \\
\hline$(-5,5)$ & 28.55 & $9.52 * * *$ & 0.33 & 18.35 *** & 13.57 & $12.65 * * *$ & * $15.07 * * *$ & $-59.84 * * *$ & $11.35 * * *$ & 2.8 . & $14.58 * * *$ & -0.82 & $8.53 * * *$ & -9.77 * & 3.54 . & -25.1 *** & * 5.59 . & -2.46 . & -2.6 . & $-19 * * *$ & * $\quad-0.91$. & -4.72 . & -1.09 . \\
\hline$(0,10)$ & 23.7 & $14.58 * * *$ & $8.83 *$ & 10.39 * & 18.56. & $4.91^{*}$ & $-9.34^{*}$ & $48.5^{* * *}$ & 3.54 . & -6.56 . & -0.91 & 0.5 . & -1.09 & -2.96 & -1.45 & -5 . & 8.69. & -2.74 & 4.3 . & $-11.6 * *$ & -4.1 . & -7.42 . & -1.24 . \\
\hline$(-10,0)$ & 20.38. & 1.35 & 0.37. & $17.32 * * *$ & -8.22 & 3.13 . & $16.85 * * *$ & $-107.7^{* * *}$ & $5.9 * *$ & 5.01. & $9.52 * * *$ & $9.07 *$ & $9.73 * * *$ & 1.11 & $11.35 * * *$ & -0.13 & 1.7. & $11.98 * * *$ & * $23.72 * * *$ & $* 13.3 * *$ & $14.58 * * *$ & * 3.84. & $3.84 * * *$ \\
\hline$(-10,10)$ & 35.7 . & $8.8 * *$ & 9.19 . & 27.71 *** & 10.34 & $8.04 * *$ & -2.61 . & -81.52 *** & $6.67 *$ & 2.54. & $8.5 * *$ & 5.89. & $9.81 * *$ & 0.78. & $11.21 * * *$ & * -2.98. & 10.26 & $8.58 * *$ & $30.6^{* * *}$ & * -1.75 . & $12.5 * * *$ & * -7.64 & 6.21. \\
\hline
\end{tabular}

$* * *$ p-value $<.01, * *$ p-value $<.05, *$ p-value $<.1$

Table 6e: The Lockdown event with Google Trends term ("Meat processor") and financial beta (GRANK Test)

\begin{tabular}{|c|c|c|c|c|c|c|c|c|c|c|c|c|c|c|c|c|c|c|c|c|c|}
\hline \multirow{3}{*}{$\begin{array}{l}\text { Events } \\
\text { Windows }\end{array}$} & \multirow{2}{*}{\multicolumn{2}{|c|}{ 19-Mar }} & \multirow{2}{*}{\multicolumn{3}{|c|}{ 21-Mar }} & \multirow{2}{*}{\multicolumn{3}{|c|}{ 23-Mar }} & \multirow{2}{*}{\multicolumn{2}{|c|}{ 26-Mar }} & \multirow{2}{*}{\multicolumn{2}{|c|}{ 27-Mar }} & \multirow{2}{*}{\multicolumn{2}{|c|}{ 30-Mar }} & \multirow{2}{*}{\multicolumn{3}{|c|}{ 1-Apr }} & \multirow{2}{*}{\multicolumn{3}{|c|}{ 2-Apr }} & \multirow{2}{*}{ 3-Apr } \\
\hline & & & & & & & & & & & & & & & & & & & & & \\
\hline & BRID & PtfCARs & MDLZ CAG & MMMB & PtfCARs & TSN & CHEF & Ptf CARs & PPC & Ptf CARs & HRL & Ptf CARs & SEB & PtfCARs & SAFM $\mathrm{I}$ & $\mathrm{KHC}$ & Ptf CARs & SYY & ALCO & Ptf CARs & CALM PtfCARs \\
\hline$(0,5)$ & 156.1 *** & * 26.81 *** & $-22 * * *-7.64 *$ & 15.52 . & $14.85 * * *$ & 1.04 . & $53.53 * * *$ & $15.54 * * *$ & 2.6 & $10.5 * * *$ & 12.52 *** & $7.93 * * *$ & $13.48 * * *$ & * 7.71 *** & $-8.3^{*}$ & -1.91 & 2.23 . & $29.63 * * *$ & 2.8 & 1.77. & $-22.5 * * *-3.61 * *$ \\
\hline$-5,0)$ & $141.6 * * *$ & * -0.69 . & $-25.6^{* * *} \quad 4.22$ & 6.1. & $7.99 * * *$ & $24.17 * * *$ & * $-67.19 * * *$ & $11.83 * * *$ & $13.27 * * *$ & * $31.25 * *$ & -5.04 & $21.78 * * *$ & $19.44 * * *$ & $* 14.73 * * *$ & $-18.3^{* * *}$ & -3.64 & $4.51 * * *$ & $9.73 * *$ & $-9 * * *$ & -0.49 & $-13.7 * * * \quad-7.88 * * *$ \\
\hline$(-5,5)$ & $269.4 * * *$ & * $18.27 * *$ & $-47.6^{* * *}-3.42$ & 21.62 . & $22.66 * * *$ & $14.52 * * *$ & * -37.46 *** & $23.52 * * *$ & $17.66 * * *$ & * $36.76 * * *$ & 5.31 & $30.77 * * *$ & $31.05 * * *$ & * $21.8 * * *$ & $-22.1 * * *$ & -3.61 & $6.97 * * *$ & $37.83 * * *$ & $-11 * *$ & 2.49 . & $-36.7 * * *-11.1$ *** \\
\hline$(0,10)$ & $274.8 * * *$ & * $28.29 * * *$ & $-37.9 * * *-5.92$ & $36.52 * *$ & $20.99 * * *$ & -5.01 & 73.96 *** & $23.24 * * *$ & 7.05 & $25.12 * * *$ & $8.3^{*}$ & $21.94 * * *$ & $39.74 * * *$ & * $15.27 * * *$ & -5.97. & -4.1 . & $5.39 * *$ & $45.22 * * *$ & 0.45 & 0.34 . & $-37.8 * * * \quad-8.93 * * *$ \\
\hline$(-10,0)$ & $197.5 * * *$ & * -5.44 ** & $-38.2 * * *-7.91$ & -16.78 . & 1.43. & 10.59 ** & -94.36 *** & $5.28 * *$ & $19.62 * * *$ & * $26.12 * * *$ & $14.45 * *$ & $30.62 * * *$ & 31.37 *** & * $22.29 * * *$ & -2.61 & $-9.39 *$ & $17.4^{* * * *}$ & $62.24 * * *$ & $16.33 * * *$ & $16.37 * * *$ & $-25.3^{* * *}-0.47$ \\
\hline$(-10,10)$ & $444 * * *$ & $15 * * *$ & $-76^{* * *}-13.8 *$ & 19.74 . & $22.42 * * *$ & -5.1 & $-44.21 * * *$ & $24.67 * * *$ & $28.47 * * *$ & * $46.25 * *$ & $20.58 * * *$ & $53.62 * * *$ & $69.25 * * *$ & * $36.91 * * *$ & -4.05 . & -11.6 . & $23.1 * * *$ & $105.9 * * *$ & $12.02 *$ & $17.91 * * *$ & $-63.6^{* * *}-9.04 * * *$ \\
\hline
\end{tabular}

$* * *$ p-value $<.01, * *$ p-value $<.05, *$ p-value $<.1$

Table 6f: The Lockdown event with market model

\begin{tabular}{|c|c|c|c|c|c|c|c|c|c|c|c|c|c|c|c|c|c|c|c|c|c|c|c|}
\hline \multicolumn{24}{|c|}{ Kolari and Pynnonen (2011) Generalised Rank Test (GRANK) without Google Trends } \\
\hline Events & \multicolumn{2}{|c|}{ 19-Mar } & \multicolumn{4}{|c|}{ 21-Mar } & \multicolumn{3}{|c|}{ 23-Mar } & \multicolumn{2}{|c|}{ 26-Mar } & \multicolumn{2}{|c|}{ 27-Mar } & \multicolumn{2}{|c|}{ 30-Mar } & \multicolumn{3}{|c|}{ 1-Apr } & \multicolumn{3}{|c|}{ 2-Apr } & \multicolumn{2}{|c|}{ 3-Apr } \\
\hline Windows & BRID & Ptf CARs & MDLZ & CAG & MMMB & \begin{tabular}{l|l} 
PtfCARs & I
\end{tabular} & TSN & CHEF & \begin{tabular}{l|l} 
PtfCARs & F
\end{tabular} & PPC & PtfCARs & HRL & PtfCARs & SEB & \begin{tabular}{l|l} 
PtfCARs & S.
\end{tabular} & SAFM & $\mathrm{KHC}$ & Ptf CARs & SYY & ALCO & PtfCARs & CALM & PtfCARs \\
\hline$(0,5)$ & 18.29 . & $21.04 * * *$ & 1.89. & 3.81 . & 9.88 . & $8.71^{* * *}$ & $6.33 *$ & $45.02 * * *$ & $8.9 * * *$ & -0.11 & 1.86. & $11.29 * * *$ & * -0.12 & -2.52 & $3.32 *$ & -1.9 . & $7.5^{*}$ & 0.9 & $11.4^{* * *}$ & 2.31 & $3.54 * *$ & -1.57 & $4.46^{* *}$ \\
\hline$(-5,0)$ & 36.8 ** & -2.85 & -4.14 & $15.68 * * *$ & -8.16 & $4.63 * * *$ & 19.04 *** & $-84.67 * * *$ & $6.63 * * *$ & 10.26 ** & $21.37 * * *$ & $-7.24 *$ & $11.52^{* * *}$ & 2.59 & $8.68 * * *$ & -13 *** & 4.61 & $3.12^{*}$ & $-6.79 *$ & $-7.74 * *$ & 1.48. & 4.61. & -0.07 . \\
\hline$(-5,5)$ & $46.21 * *$ & $10.92 * * *$ & -2.25 & $19.5^{* * *}$ & 1.72 & $13.33 * * *$ & $16.66 * * *$ & -60.67 *** & $13.52 * * *$ & $11.87^{* *}$ & $20.32 * * *$ & 1.76 & $13.6 * * *$ & 0.77 & $11.88 * * *$ & $-11.3^{*}$ & $12.67 * *$ & $4.39 *$ & 6.18 . & $-10.3^{* *}$ & $6.04 * *$ & -0.43. & 3.53 . \\
\hline$(0,10)$ & 30.56 . & $20.18 * * *$ & 9.35 ** & $18.11 * * *$ & 21.14 & $10.66 * * *$ & 2.92 . & 55.92 *** & $12.03 * * *$ & 4.73 & 7.57 *** & 3.77. & $4.63 *$ & 5.83 & $5.84 * *$ & 7.01 . & 14.86 *** & 2.97 & $13.49 * * *$ & -1.2 & 3.82 . & -0.24 . & 5.33 ** \\
\hline$(-10,0)$ & $65.58 * * *$ & $-6.92 * * *$ & -7.05 & 9.26 . & $-37.36 * * *$ & -3.08 & 4.71. & $-118.4 * * *$ & -1.08 & $12.36 * *$ & $11.43^{* * *}$ & 11.36 ** & $14.47^{* * * *}$ & 1.74 & 13.83 **** & 6.84 & 5.48 . & $14.6^{* * *}$ & $31.66 * * *$ & $18.4^{* * *}$ & * $19.48 * * *$ & 7.34 & $12.64 * * *$ \\
\hline$(-10,10)$ & 87.26 *** & $5.63^{*}$ & 2.31 . & $27.37 * * *$ & -16.22 & 7.57 ** & -1.09. & -83.52 *** & $8.95 * * *$ & $18.8 * *$ & $16.1^{* * *}$ & $12.83 * *$ & $21.3^{* * *}$ & 8.26. & $19.55 * * * 1$ & $17.47 * *$ & 20.9 *** & $17.94 * * *$ & $46.72 * * *$ & $12.4^{* *}$ & 24.32 *** & 3.62. & 17.11 *** \\
\hline
\end{tabular}

$* * *$ p-value $<.01, * *$ p-value $<.05, *$ p-value $<.1$ 
2

6

7

8

9

Reply to reviewers' comments:

\section{Email from Dr. Todd Kuethe.}

Reviewer(s)' Comments to Author:

Referee: 1

Recommendation: Minor Revision

Comments: Please see my scoring and associated comments above. I enjoyed reading your paper.

\section{Additional Questions:}

Comment: 1. Originality: Does the paper contain new and significant information adequate to justify publication?: Yes - it is original \& timely

Response: Thank you for your comments.

Comment: 2. Relationship to Literature: Does the paper demonstrate an adequate understanding of the relevant literature in the field and cite an appropriate range of literature sources? Is any significant work ignored?: Yes - existing literature is well incorporated

The 2020 JARE paper (https://ageconsearch.umn.edu/record/298436 ) by Moon \& Tonsor on the impact of E.coli recalls is another recent paper in this broader "event impact" space for the meat industry.

Response: We have incorporated the suggested article (page 3) as such:

"Similarly, Moon and Tonsor (2020) investigated the effect of E. Coli recalls on prices of the U.S beef industry on 66 cases for over 14 years. Results show varying reactions to the change in the price of beef products to E. coli recalls across the different levels of vertical connection. Aggregated products being less affected by the recall event than disaggregated beef products." 
Comment: 3. Methodology: Is the paper's argument built on an appropriate base of theory, concepts or other ideas? Has the research or equivalent intellectual work on which the paper is based been well designed? Are the methods employed appropriate?: Yes - the event study approach is well-documented and appropriately applied here

Comment: 4. Results: Are results presented clearly and analyzed appropriately? Do the conclusions adequately tie together the other elements of the paper?: Yes - results are presented and discussed clearly. I appreciate the on-point approach that is supported by several tables \& figures.

Comment: 5. Implications for research, practice and/or society: Does the paper identify clearly any implications for research, practice and/or society? Does the paper bridge the gap between theory and practice? How can the research be used in practice (economic and commercial impact), in teaching, to influence public policy, in research (contributing to the body of knowledge)? What is the impact upon society (influencing public attitudes, affecting quality of life)? Are these implications consistent with the findings and conclusions of the paper?: There indeed are many timely implications. In fact, given ongoing concerns around industry structure the findings here on no statistically significant effect on average abnormal returns are key to disseminate.

Comment: 6. Quality of Communication: Does the paper clearly express its case, measured against the technical language of the fields and the expected knowledge of the journal's readership? Has attention been paid to the clarity of expression and readability, such as sentence structure, jargon use, acronyms, etc.: Yes

Comment: Please check spelling of Lee Schulz throughout the paper. Response: We have rectified the spelling throughout the paper.

Comment: Please clarify that the Lusk, Tonsor, \& Schulz AEPP paper also makes reference to stock market performance of publicly-traded meat companies. 
Response: We have clarified by adding the following to (page 12, second paragraph four last sentences): "Lusk et al. (2020) discuss this effect arguing that stock market prices of meat processors did not experience large declines due to Covid-19 events.

Page 11 from lines 10 to 11: "In fact, Lusk et al. (2020) find that although there were outbreaks in processing firms, leading to plant closure of meatpacking plants, it did not obstruct others from producing meat products". Other firms were still able to trade to meet up with the demand. 
Referee: 2

Recommendation: Major Revision

Comments:

This paper revisits the begging of the Covid-19 pandemic in the US to observe how the stock prices of meat processing companies faired from January to July. With the use of Google trends data, the expected returns if the pandemic had not occurred of 14 meat processing companies are calculated and compared to their actual returns to provide a clear picture of the discrepancies in stock prices these businesses saw due to Covid-19. Four key dates are focused on to examine price changes: the announcement of Covid-19 being a global pandemic, the first case of Covid exposure among plant workers, Covid-19 outbreaks at the different companies' plants, and then the announcement of lockdowns. Building upon past research on markets responses to disease outbreaks the authors find that nationwide events had little effect on the companies' stock returns but outbreaks at different companies' facilities had some negative impacts on their stock returns.

Response: Thank your comments.

Comment: The authors describe all the companies in this study as meat processors, however not all of the companies reviewed fit the description of a meat processor that the authors lay out in their article. Sysco, for example, is a food service company that does little to no meat processing of its own but rather distributes meat products to restaurants and other venues with food service. The authors should revisit the companies in the study as some of them appear to fall more into the food distribution category as opposed to food processing. Another issue is I am unsure if some of the processing companies included even produce meat products. Cal-Maine appears to just be an egg producer and I was unable to tell if Mondelez International produces any meat products. The companies used in this study needs to be better defined.

Response: We have included extra information on the definition of meat processors (page 5, second paragraph lines 3-6). "Specifically, we consider under meat processors companies those 
that are involved in one or more stages of meat processing (i.e. animal slaughtering, packaging, and processing into products, such as sausage or lunch meat, delivers to retail stores (Encyclopedia of Food Microbiology, 2014))."

Regarding your concerns about the companies Sysco, Cal-Maine, and Mondelez International, we have carefully selected these following past studies on meat processors (e.g. Thompson et al. (2019), as well as data from the industry (see top 100 meat and poultry processors) and USDA's list of meat and poultry firms. Following, we discuss each of the mentioned companies individually:

Sysco: Our choice of this company is due to their mention in the sample of meat processors in Thompson et al. (2019), their $4^{\text {th }}$ position as the top 100 meat and poultry processors, and the selection of USDA's list of meat and poultry firms. USDA classifies SYSCO as Meat and Poultry processing through DiTo's.

(https://www.fsis.usda.gov/sites/default/files/media file/202108/MPI Directory by Establishment Name.pdf)

Cal-Maine Foods Inc: is a wholesale egg, poultry slaughtering, and processing slaughterhouses, meat and poultry and seafood processing (https://www.macraesbluebook.com/search/company.cfm?company=487013)

Mondelez International, Inc: selected from related literature (Thompson et al., 2020), according to the NAICS Profile Page and Mergent Intellect Database, Mondelez International, Inc is classified under "311612 Meat Processed from Carcasses".

We believe that removing these companies from the sample could reduce our sample size considerably and also remove the possibility of comparing our results to those of past studies. In general, companies diversify their business to reduce risk and, as such, may act in different industrial sectors. We included this factor as a limitation:

"However, it is important to shed light on some limitations of our research. First, we only consider U.S. publicly traded meat processing companies; as such, important privately owned meat processors were not considered (e.g. Smithfield). Secondly, meat processors in our study may produce and distribute other products that are not meat products. As such, companies with greater diversity in products other than meat may have suffered a lesser or different impact from 
the events than those with a larger share of activities devoted to meat processing. We suggest that future studies focus on developing an event study methodology that can account for how diversified a company's product portfolio is." (page 14 or last paragraph from line 6 of the conclusion)

Comment: At the beginning of section two "Impact of Covid-19 on meat processing industries," the authors review past research on financial markets response to animal borne illnesses and cite a few papers, yet the authors don't include any of the findings from those studies. The authors draw the distinction between those papers being on the topic of animal illnesses and Covid-19 being a virus that affects humans, but I don't find that difference to be sufficient to leave out past research on market's response to pathogens. As a reader, I would like to see how the results in this study compare to results from previous research in this area

Response: Agreed, this section now reads as follows (page 3, first paragraph Section 2):

"In the past decades, studies have focused on food-borne diseases and their consequences on financial markets. For instance, Pendell and Cho (2013) studied the reaction of stock markets to the Korean foot and mouth disease outbreaks between 2000 and 2010. They found that stock market reactions to the event was gradual with the cumulative abnormal returns (CAR) being more statistically significant than one day abnormal returns (AR). Jin and Kim (2008) analyzed the effects of the Bovine Spongiform Encephalopathy (BSE) outbreak on the security values of agribusiness and processing firms in the U.S. They find BSE had a negative impact on the beef industry and a negligible impact on companies that did not produce beef. Thompson et al. (2019) examined how the 2014-2015 highly pathogenic avian influenza (HPAI) affected agribusiness' stock markets. Results showed negative abnormal returns ranging from $2 \%$ to $4 \%$ for publicly traded meat processors' equities mainly after the event occurred. The impact was even higher (over $5 \%$ ) for firms specialized in poultry products."

Comment: The authors lay out the case for the use of search data as a variable to use in forecasting, but I am not sure that the term "coronavirus" is the best predictor of stock returns for meat processors. Based on the regression model the authors use the stock market index and the 


\section{$\underline{\text { Minor Comments }}$}

Comment: Please provide the company names alongside the stock tickers. Maybe add a table to allow the reader to match the ticker names to the companies because there is nothing that serves this now.

Response: We added the column "Stock Ticker" to Table 1(a). (page 2 of Tables and Graphs)

Comment: Information on how the food company stocks moved in relation the S\&P 500 prior to Covid in normal market conditions could highlight the findings and give good background information for the reader on the typical behavior of these stocks.

Response: We extended the x-axis of Figure 1 to include pre- and post- the WHO announcement of Covid-19 as a pandemic. (page 7 of Tables and graphs) 


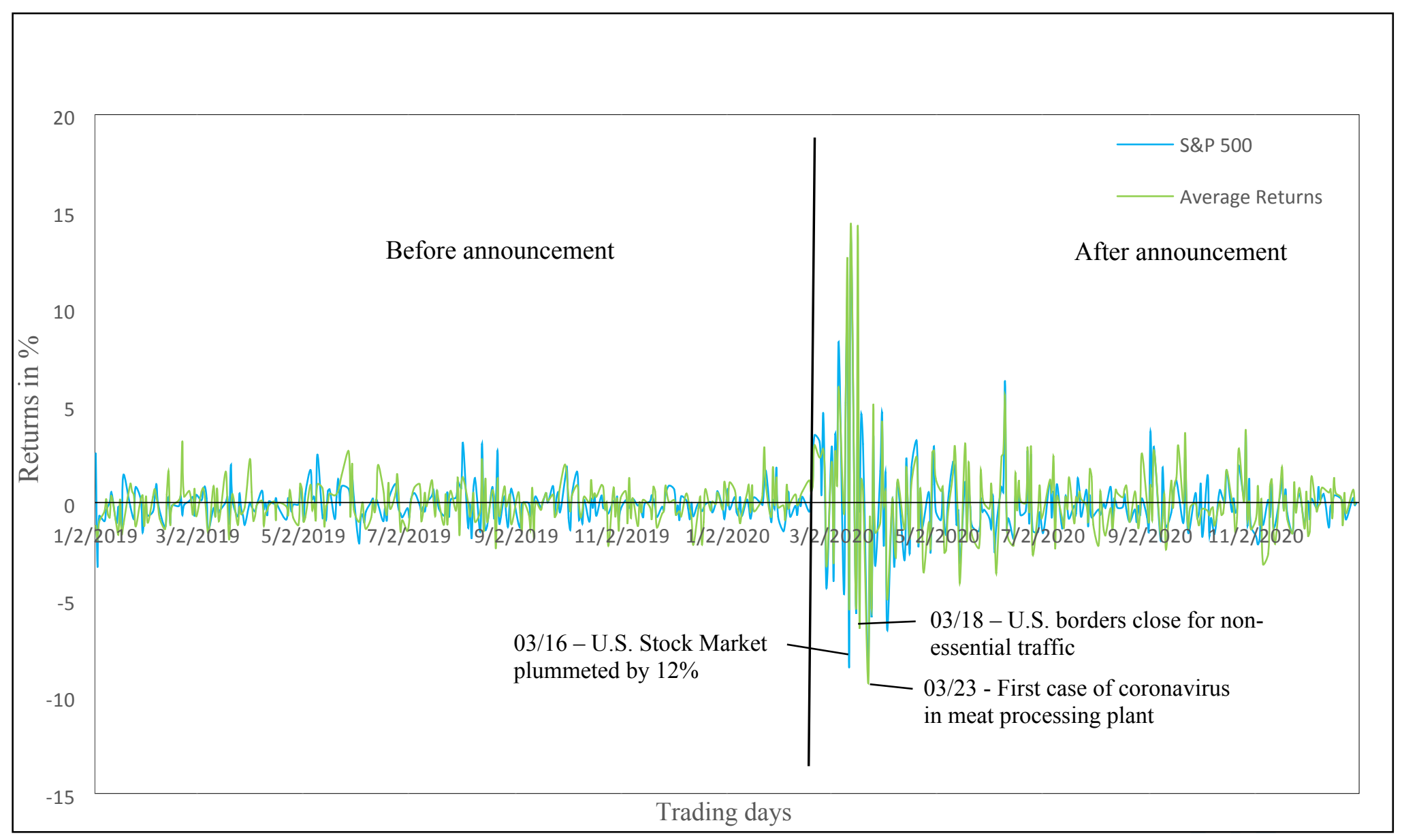

Source: Yahoo Finance and Mergent Online. Returns calculated by the authors. Note: the black line marks 3/11/2020.

Figure 1: The average stock returns of meat processing firms and S\&P 500 from January 2 to July 2, 2020 (before and after the W.H.O announcement of Covid-19 as a pandemic) 
Comment: Are the stock returns in percentage or pure dollar amounts? It isn't exactly clear, even in the methods section.

Response: In the data and descriptive statistics section we added the information "All returns are in percentages.”. (page 5)

Comment: In figure 1, think about changing the color of the lines pointing from the labels to the events. They are hard to read. Consider if the 6/11 bullet is necessary. Avoid colloquialisms like "wall street."

Response: In figure 1, we have removed the 6/11 bullet, and the lines pointing from the labels to the events are not in bold to make it easy to read. Also, 'wall street', has been changed to the '’U.S. Stock Market', (page 2 from Tables and graphs)

Comment: In figure 2, graphs a and b are in the wrong order. These graphs need more explanation. There is no key to understand what the different lines represent which limits their effectiveness. These graphs are featured prominently in the results section but need to be improved so the reader can clearly understand them.

Response: We fixed the order of the graphs and added a legend to each graph indicating that the solid line is the abnormal returns (in this case, the cumulative abnormal returns) and that the dotted lines mark the lower and upper confidence intervals. In the notes, we further explain this. We have also worked on the caption of the graphs so as to become clearer to the reader. (pages 3 -6 from Tables and graphs).

Comment: Review the citations to ensure they are accurate. The authors cite (Staff, 2020) on pages 2 and 3 but I can not find it in the references. Additionally, on page 5 research on forecasting with google index data is attributes to (Jin \& Kim, 2008) when it is actually from (Jun et al, 2017).

Response: We fixed all citations and added 'KY3 News, 2020'. Also, we have corrected the source on forecasting with google trends data to reference Jun et al., 2017 instead of Jin \& Kim., 2008 as initially stated. 
Comment: There should be consistency between stock return in equation 1 and expected returns in equation 2. The different labels are confusing for the reader.

Response: We have made the following changes (page 8):

Abnormal Return $_{i t}=$ Actual Returns $_{i t}-$ Stock Return $_{i t}$

"Where the actual stock returns are observed from the event window and the expected returns predicted by equation (1) (i.e. Stockreturn ${ }_{i t}$ is the estimated stock returns)."

Comment: The conclusion section is abrupt and doesn't cover the full scope of the results of the paper or explain how it the findings fit in with past research

Response: We have updated the conclusion as follow (page 13-14):

"This study examined the effects of events that disrupted supply chains on the stock market returns of meat processing companies during the pandemic. We apply the event study approach to investigate events such as the pandemic announcement, the first case of COVID-19 outbreak in meat processors, the first case of an outbreak in individual meat processors, and the first lockdown days. Results show that nationwide events had, on average, no statistically significant effect on the cumulative average abnormal returns of meat processing companies. Individually, however, some firms experienced negative cumulative abnormal returns. We also found that Covid-19 related events to individual companies had only a temporary negative effect on the meat processing returns and sometimes positive effects after the event. The findings of Moon and Tonsor (2020) on the impact of E. coli recalls on the U.S beef industry are in line with these results. They find a temporary negative effect on the U.S beef industry for about four days, followed by a quick recovery to expected returns. Similarly, the findings of our study are consistent with those of Thompson et al. (2019), that found heterogeneity in the reactions of investors based on the nature of the events and the timing of the event during the period of study. Furthermore, our results are supported by the findings of Jin \& Kim (2008) on the effects of the BSE outbreak on the security 
values. They also find that while the events negatively impacted some firms, other firms experienced stronger positive benefits.

The use of Google Trends allowed for a better representation of investor's perceptions and improved the estimation of expected returns. Like Brodeur et al., 2021 and Salisu et al.(2021), we argue that the variation in google searches reflects both the investors' knowledge and concern about the pandemic and its impact on the stock market. Thus, in general, investors were able to predict the behavior of the stock markets. The use of the term and of other traditional financial concepts can also help improve the prediction of expected returns. However, it is important to shed light on some limitations of our research. First, we only consider U.S. publicly traded meat processing companies; as such, important privately owned meat processors were not considered (e.g. Smithfield). Secondly, meat processors in our may produce and distribute other products that are not meat products. As such, companies with greater diversity in products other than meat may have suffered a lesser or different impact from the events than those with a larger share of activities devoted to meat processing. We suggest that future studies focus on developing an event study methodology that can account for how diversified a company's product portfolio is. This study provides insight to investors on the behavior of industry returns from events such as outbreaks that can disrupt supply chains. We also provide insight into how the use of search trends can improve the estimation of expected stock market returns."

Comment: Grammar - On page 10 (11 in the pdf) right after (figure 1) the authors leave out “interval” from confidence interval. Response: We added it.

\section{Additional Questions:}

Many of the additional questions touch on questions asked earlier under major reviews. You will notice that we have referred back to the answers provided there.

Comment: 1. Originality: Does the paper contain new and significant information adequate to justify publication?: Yes, this paper attempts to study how the stock returns of large agribusiness companies operating in the meat industry were affected by Covid-19. It is an event study approach which is appropriate in this context and uses a variety of dates from the announcement 
Comment: 3. Methodology: Is the paper's argument built on an appropriate base of theory, concepts or other ideas? Has the research or equivalent intellectual work on which the paper is based been well designed? Are the methods employed appropriate?: The authors use appropriate event-based methodology. The KP and GRANK tests appear to be standard for conducting tests on abnormal stock returns. The regression model used to predict each companies expected stock returns incorporates google search data with the term "coronavirus". The authors argue that investors have to do research when making decisions and thus their researched terms will appear in google search trends. I find it hard to accept that the term coronavirus would be the most appropriate term to use for this study as it was a global pandemic with hundreds on millions of people searching that term every day, most of them who have no interest in investing/speculating on agribusiness stocks. I think that more specific terms like "meat producers" or "packing plant shutdowns" would be more appropriate. Additionally, they could incorporate more traditional finance concepts like the combined beta of their basket of companies to help forecast their expected returns.

Response: Thank you for your comments. We have addressed this point earlier under major revisions.

Comment: 4. Results: Are results presented clearly and analyzed appropriately? Do the conclusions adequately tie together the other elements of the paper?: The authors use figure 2 graphs to help describe their results, but I find these graphs to be difficult to understand as there 
isn't much description as to what the lines stand for. This limits their effectiveness. Aside from the graphing issue the results are presented clearly and line up with the tables. One potential issue in the results is due to the companies included in the study. Some of the companies are not true meat processors but rather meat and food distributors. Tyson, for example, is a meat processor that slaughters animals but others, like Sysco, are food distributors that sell food to restaurants and food venues. The stocks of these companies would likely have different reactions to processing infections or lock downs because they do fundamentally different things. Response: Thank you for your comments. Please see our answer explaining how the companies were chosen and on how we define meat processor.

Comment: 5. Implications for research, practice and/or society: Does the paper identify clearly any implications for research, practice and/or society? Does the paper bridge the gap between theory and practice? How can the research be used in practice (economic and commercial impact), in teaching, to influence public policy, in research (contributing to the body of knowledge)? What is the impact upon society (influencing public attitudes, affecting quality of life)? Are these implications consistent with the findings and conclusions of the paper?: The authors use figure 2 graphs to help describe their results, but I find these graphs to be difficult to understand as there isn't much description as to what the lines stand for. This limits their effectiveness. Aside from the graphing issue the results are presented clearly and line up with the tables. One potential issue in the results is due to the companies included in the study. Some of the companies are not true meat processors but rather meat and food distributors. Tyson, for example, is a meat processor that slaughters animals but others, like Sysco, are food distributors that sell food to restaurants and food venues. The stocks of these companies would likely have different reactions to processing infections or lockdowns because they do fundamentally different things.

Response: Thank you for your comments. We agree that stocks have different reactions, but these reactions are more likely due to the diversification in the sectors in which the company operates. For instance, even though Sysco is a food distributor, it also does meat and poultry processing through DiTo's according to the USDA list of meat and poultry firms. Our choice of 
1

2

3

4

5

6

7

8

9

10

11

12

13

14

15

16

17

18

19

Sysco also comes from related literature of Thompson et al. (2019) and The Top 100 meat and poultry Processors (2020)

Comment: 6. Quality of Communication: Does the paper clearly express its case, measured against the technical language of the fields and the expected knowledge of the journal's readership? Has attention been paid to the clarity of expression and readability, such as sentence structure, jargon use, acronyms, etc.: There are some awkward sentences or parts that don't read as well but as a whole, the paper is understandable and accessible to a fairly wide audience. Some more proofreading on the author's part could sort out some of the issues apart from what I have addressed in my comments.

Response: Thank you for your comments. You will notice we have re-written and edited various parts of the manuscript. 